(Aus dem anatomischen Institut in Strasshurg.)

\title{
Ueber Bau und Verhornung der menschlichen Oberhaut.
}

\author{
Von \\ Dr. Franz Weidenreich, \\ Assistent am anatomischen Institut. \\ Hierzu Tafel VII u. VIII.
}

Nach dem Stande unserer heutigen Kenntnisse müssen wir die menschliche Epidermis als ein Gewebe betrachten, das sich ans ïbereinander geschichteten Lagen epithelialer Zellen zusammensetzt, die gegen die Peripherie einer allmählich fortschreitenden Veränderung nach der morphologischen und physiologischen Seite unterworfen sind. Dieser Process characterisirt sich als ein degenerativer, welcher in der zunehmenden mangelhaften Ernährung seinen Grund hat und schliesslich zum völligen Absterben der Zelle führt; el' unterscheidet sich aber von ähnlichen Vorgängen im wesentlichen dadurch, dass die todte Zelle nicht einer Auflösung anheimfällt, sondern sich infolge mechanischer Einwirkung aus dem allgemeinen Zellverbande des Körper's loslöst; dabei ist aus einem kernhaltigen, weichen und protoplasmareichen Gebilde ein kernloses, trockenes und für chemische Reagentien äusserst widerstandsfähiges Schüppchen geworden, das man als verhornt bezeichnet. Der Ersatz für die von der Oberfläche des Körpers verloren gegangenen Zellen wird von einer am weitesten basal gelegenen Zelllage geliefert, die sich ausschliesslich die Fähigkeit der Fortpflanzung bewahrt hat. Indem die Epidermiszellen von dieser Basalschicht nach der Peripherie zurücken, vollziehen sich in ihnen die oben angedeuteten Umwandlungen, und da diese schichtweise ihre am meisten characteristische Ausbildung erfahren, imponiren die Zellreihen jeweils als besondere Lagen, die sich mehr oder weniger scharf von den darunter- oder darüberliegenden abzugrenzen scheinen und die man nach dem Vorwiegen des einen oder des anderen Merkmals mit entsprechenden Namen bezeichnet hat. Eine Untersuchung über das Wesen der 
Verhornung kann sich also niemals ausschliesslich auf eine dieser Lagen beschränken, sondern muss sich auf die ganze Epidermis ausdehnen, um eine Ableitung des Gewordenen aus dem Vorhergehenden finden zu können. Diesem Grundsatz entsprechend habe ich alle Schichten der Epidermis zur Untersuchung herangezogen, deren Resultate ich im Folgenden mittheile; ich werde dabei nit der Beschreibung des Stratum Malpighi beginnen, um dann der Reihenfolge nach die anderen Schichten abzuhandeln. Zuvor balte ich es jedoch für nothwendig, mich bier über die Untersuchungsmethoden kurz zusammenfassend zu äussern; auf Einzelbeiten werde ich noch an den betreffenden Stellen der Abhandlung zurückzukommen haben.

\section{Untersuchungsmethoden.}

Was zunächst das Material angeht, so verwendete ich nur Epidermis, die entweder durch Operation gewonnen und sofort in die Fixirungsflüssigkeit eingelegt worden war oder aber sobald als möglich nach dem Tode, höchstens aber sechs Stunden nach demselben, der Leiche entnommen wurde. Zur Anfertigung von Schnitten bediente ich mich stets nur des Materials aus der ersten Quelle, während das aus der letzteren für Maceration und Verdanung rerwendet wurde. Gestützt auf die Angaben von Zander(66) habe ich geglaubt, davon absehen zu können, die Oberhaut aller Körperstellen zur Untersuchung heranzuziehen und mich nur auf Vola manus und Planta pedis einerseits, auf Rücken-, Schenkel- und Brusthaut andererseits beschränkt. Auch von der Haut der Planta pedis der Katze wurden Präparate angefertigt. Schnitte von frischem Material wurden nur zur Orientirung uiber Lagebeziehung und Beschaffenheit von Keratohyalin und Eleidin benutzt.

Als Fixirungsflüssigkeit verwendete ich Alkohol, Formol in $10 \%$ Verdünnung des käuflichen Formalins, Zenker'sche Flüssig. keit und Sublimat-Kochsalzlösung; über den Werth des einen oder des anderen Mittels werde ich mich im Verlaufe der Abhandlung zu äussern haben. Zur Einbettung bediente ich mich des Paraffins; Versuche mit überhitztem Paraffin nach Graf Spee hatten weder Vor- noch Nachtheile gezeigt. Bekanntlich huldigt man vielfach der Ansicht, dass zur Einbettung Celloidin vorzuziehen wäre, weil die Härte der Stlicke es sonst erschwere oder unmöglich mache, genügend dünne Schnitte zu erhalten. Diese Befürchtung 
habe ich indessen nicht bestätigt gefunden, vielmehr ist es mir fast immer gelungen, eine Schnittdicke von 2,5 oder $5,0 \mu$, gelegentlich sogar noch eine geringere zu erreichen. Dabei sind allerdings gewisse Kautelen zu berücksichtigen. Vor allem empfiehlt es sich, die Kutis schon vor dem Einlegen soweit als möglich zu entfernen, was man am besten dadurch bewirkt, dass man die Epidermis mittels eines scharfen Rasirmessers flach abtrïgt; dann dürfen die Stücke nicht zu gross sein und niemals länger als absolut nothwendig in den durchtränkenden Medien bleiben, um unnöthiges Hartwerden zu vermeiden. Beim Schneiden stellt man das Messer schräg, etwa in einem Winkel von $45^{\circ}$ zum Schlitten und schneide stets, wie K romayer (30) angibt, vom Stratum corneum gegen die Kutis. Für die weitere Behandlung empfiehlt es sich jedoch nicht, dessen Angaben zu befolgen und die Schnitte in Schalen von Paraffin $z u$ befreien und dort $z u$ färben, sondern nach den allgemeinen Regeln der histologischen Technik mit Wasser aufzılkleben und auf dem Objectträger weiter zu behandeln.

Als Färbemittel bediente ich mich theils der K roma yer'schen Modification der Wei g e rt'schen Färbung(30), die mir ausgezeichnete Resultate gab, dann aber vorwiegend der Heiden ha in'schen EisenHämatoxylinfärbung, der ich eine Behandlung mit Bordeaux vorangehen oder eine solche mit Rubin folgen liess; mit dieser Methode ist es mir gelungen, einzelne Gebilde in besonderer Schönheit und Deutlichkeit zur Anschauung zu bringen. Weiterhin färbte ich noch mit Hämalaun und der van Gieson'schen Picrinsäure-Fuchsinmischung. Ein Versuch mit dem von Herxheimer (22) empfoblenen Cresylechtviolett gab keine günstige Resultate.

Macerirt wurde in der Wärme entweder in physiologischer Kochsalzlösung oder in Eindrittelalkohol, dem bis zur Sättignng Salicylsänre zugesetzt war; dabei wurde mit Vortheil eine Spur Methylviolettlösung der Macerationsflüssigkeit beigemischt, da die Eigenschaft der Keratohyalinköruer, diesen Farbstoff begierig aufzunehmen, die Orientirung über die Lage der zur Untersuchung entnommenen Hornzellen wesentlich erleichtert. Die isolirten Zellen wurden entweder ungefärbt betrachtet oder mit einer concentrirten wässerigen Methylviolettlösung oder auch nach den An- 
gaben von Rausch (49) mit polychromsaurem Methylenblau behandelt.

Zur Verdauung gebrauchte ich die von Unn a (63) empfohlene Pepsin-Salzsäuremischung (Acid. muriat. 1,0, Pepsin 0,5, Aqu. 100,0) bei einer Temperatur von $42^{\circ}$, der die Objecte 12 Stunden bis 8 Tage oder länger ausgesetzt blieben; die Verdauung wurde sowohl an ganzen Stiicken der Epidermis als auch an Schnitten vorgenommen. Im ersteren Falle wurden die Zellen dann entweder isolirt und ungefärbt oder nach den obigen Angaben gefärbt untersucht, oder nach mehreren Tagen, ehe der Zellverband zu sebr gelockert war, ausgewaschen, in Alkohol gehärtet und dann geschnitten. Bei der Verdauung der Schnitte zeigte sich der Nachtheil, dass die verdaute Hornschicht trotz sorgfältiger Entfettung des Objectträgers sich loslöste und davon schwamm; diesem Missstande begegnete ich mit Erfolg dadurch, dass ich die Objectträger nicht in ein Glas mit der Verdauungsflüssigkeit stellte, sondern diese tropfenweise auf die vom Paraffin befreiten Schnitte goss und dann den Träger wagerecht in einer feuchten Kammer in den Brutofen brachte. Die verdauende Wirkung war dieselbe, nur dass jetzt die Schnitte in der Mehrzahl auf dem Glase haften bleiben; in diesem Falle geschah die weitere Behandlung nach Abwaschen der Verdauungsflüssigkeit wie üblich; hatten sich aber doch noch einzelne Schnitte losgelöst, so wurde die Verdauungsflüssigkeit mit Filtrirpapier abgesogen und durch Wasser ersetzt, das dann wieder zum Aufkleben diente. Die Färbung solcher Schnitte geschah mit Hämalaun oder $\mathrm{H}$ e iden ha in schem Eisenhämatoxylin.

\section{Stratum Malpighi.}

Die unterste Schicht des Strat. Malp. besteht bekanntlich aus eigenthümlichen cylinderförmigen Zellen, die der Kutis unmittelbar aufsitzen. Herxheimer (21) gelang es, in dieser Lage mit Hilfe der W e igert'schen Fibrinmethode lange, sp i raliggewundene Fäden nachzuweisen, die sich 2 bis 3 Zellreihen tief in die Epidermis hinein fortsetzen sollten. Während E d d ow e s (11) diese Spiralen für Fibrin hielt, dem eine intercellulare Lage zukäme, sprachen sie $\mathrm{K}$ ro ma yer (28) und $R$ abl (42) für echte Protoplasmafasern an, Herxheimer und Müller (24) glauben sie als Zellconturen auffassen zu müssen, derart, dass sie 
Anschnitte einer homogenen, die Zelle umschliessenden Membran wären. Dieser Standpunkt wurde in einer späteren Arbeit (22) von $\mathrm{H}$ e $\mathrm{r} \times \mathrm{h}$ e i m e r dahin präcisirt, dass diese Membran nur "verdichtetes und stärker tingirbares " Protoplasma wäre. Nach B eneke (3) sind die Fasern ebenso wie die des ubrigen Strat. Malp., denen er sie also gleichstellt, cuticulare, membranartige Bildungen; für Kunstproducte infolge der bei der Weigertschen Fibrinmethode zur Anwendung gebrachten schrumpfenden Reagentien, wie Alkohol, Anilin und Xylol sind sie von $\mathrm{Ehr}$ $\mathrm{mann}$ (12) und $\mathrm{S} \mathrm{ch} \mathrm{ü} \mathrm{tz} \mathrm{(54)} \mathrm{gehalten} \mathrm{worden.}$

Ich habe die fraglichen Spiralen auf Schnitten von Haut, die in Alkohol oder Zenker'scher Flüssigkeit gehärtet, 2,5 $\mu$ dick geschnitten und mit He i d e $\mathrm{n}$ h a in'schem Eisenhämatoxylin bei nachfolgender Rubinfärbung behandelt war, ebenso deutlich wie mit der Kroma y er'schen Methode darstellen können. Fig. 1 gibt eine Stelle eines derartig gefärbten Präparates wieder. Die Möglichkeit, die Fasem mit einer von dem Weiger t'schen Verfahren oder seinen Modificationen verschiedenen Färbung darzustellen, entkräftet sofort die Annahme derer, die sie für Artefacte halten. Die austrocknende Wirkung des Anilius und Xylols, mit denen die Schnitte bei der Färbung überhaupt nicht in Berülirung kommen, kamn also ihre spiralige Form nicht herbeiführen. Das Einzige, was noch etwa eine Schrumpfung bei der obigen Behandlung verursachen könnte, wäre die Fixirung und diese Möglichkeit wäre bei den mit Alkohol fixirten Präparaten a priori zuzugeben. Nun erhält man aber die Spiralen in gleicher Weise, wenn man den Alkohol ausschaltet und die Hautstücke in Zenker'scher Flïssigkeit fixirt; an Stelle der vielleicht schrumpfenden, tritt dann in letzterem Mittel eher die quellende Wirkung der in ihr enthaltenen Müller'schen Flüssigkeit und des Eisessigs. Wenn man einen Unterschied zwischen den nach der alten und dell nach meiner Angabe dargestellten Fasern constatiren will, so würde er höchstens darin bestehen, dass die Spiralen etwas dünner und weniger stark gewunden erscheinen; die Differenz ist jedoch nach dieser Seite hin, wie die Abbildung zeigt, nur eine minimale, sodass ich glaube, soviel als feststehend aufstellen zu können: Die Herxheimer'schen Spiralensind keine durch die Fixation oder durch das Färbeverfahren bedingten Kunstproducte; sie sind von Natur. 
aus spiralförmig, auf die Deutlichkeit ihrer Form übt dagegen die Behandlung einengeringen Einfluss a us.

Die Frage nach dem intra- oder intercellularen Verlauf kann auf Grund derselben Präparate rasch erledigt werden. Niemals verlaufen die Fasern innerhalb des Intercellularraums zwischen zwei Zellen. Man sieht allerdings gelegentlich Bilder, wie sie in Fig. 1 bei a dargestellt sind, dass nämlich eine einzelne Spirale ohne Zusammenhang mit einer Zelle erscheint; auf die Deutung. dieses Phänomens werde ich unten zurückkommen. Dass es sich hiebei jedoch nicht um ein isolirtes, sondern um ein einer Zelle angehöriges Gebilde handelt, wird ohne weiteres klar, wenn man beachtet, dass eine solche Faser beiderseits von einem von Brücken durchzogenen Iutercellularraum umgeben ist. Spiralen ohne deutliche Beziehung zı einer Zelle habe ich niemals sehen können.

Die Ansicht Ed dowes', dass die Spiralen aus intercellular gefalltem Fibrin beständen, scheint mir durch $\mathrm{Her}$ h e i m e r and $\mathrm{M}$ ülle r genügend widerlegt; von einer intercellularen Lage kann, wie eben gesagt, keine Rede sein.

Was nun die Art der Fasern betrifft, so halte ich mit $\mathrm{Kr} 0$ mayer und $R$ abl für feststehend, dass es sich um e cht c Protoplasmafasern handelt. Ihren Verlauf hat Kroma ye $r$ genau beschrieben; ich babe dem nichts hinzuzufügen, Letzterem gegenubber möchte ich nur ihre durchaus periphere Lagerung hervorheben, so dass auf einem Halbirungsschnitt durch die Zelle parallel mit der Faserrichtung niemals noch eine Zone faserlosen Protoplasmas gegen den Intercellularraum hin $\mathrm{zu}$ beobachten ist. Auch auf Querschnitten bilden die Fasern stets einen peripheren Ring um die Zelle. Aus eben solchen Schnitten geht aber auch hervor, dass nicht, wie $\mathrm{Kr} 0$ m a y e $r$ (31) anzunehmen scheint, das Protoplasma nur aus Fasern besteht, vielmehr ist gelegentlich zwischen ihm und dem Kern eine allerdings dünne Lage von homogenem Protoplasma nachweisbar, in der ich wie Herxheimer und Müller ab und zu feine Fasern beobachten konnte. Jedenfalls sind die Spiralen nicht als Querschnitte einer Membran zu betrachten d. h. einer hom ogenen Schicht differenzirten Protoplasmas; dagegen spricht einmal, dass es nie gelingt, eine Flächenansicht einer solchen Membran zu Gesicht zu bekommen; stets baben die Zellen, 
die sich von ihrer Vorderfläche präsentiren, einen faserigen Bau ( $b$ bei Fig. 1 gibt davon ein deutliches Bild); zweitens aber zeigt ein Querschnitt, der genau senkrecht zum Verlauf der Spiralen getroffen ist, nie einen continuirlichen Kreis, sondern setzt sich aus einzelnen Punkten zusanmen, die eben Querschnitte von Fasern darstellen, zwischen welchen homogenes Protoplasma nachweisbar ist. Meine Bilder stimmen darin völlig mit denen K romayers überein, so dass ich von einer Wiedergabe derselben Abstand nehmen kann. Gleichmässigen, ringförmigen Conturen, wie sie Herxheimer und Müller (Taf. IV Fig. 3) abbilden, können zweierlei Fehlerquellen zu Grunde liegen; einmal werden solche geschlossenen Ringe vorgetäuscht, wenn der Schnitt nicht genau senkrecht zur Faserrichtung geführt ist, weil unan dann keine isolirten Punkte, sondern kurze Striche erhält, die im optischen Bilde scbon bei Schnitten von etwas über $5 \mu$ an den Enden in einander uberzugehen scheinen, dann aber auch, wenn der Schnitt nicht genügend differenzirt ist, weil dann die zwischen den Fasern gelegenen Protoplasmatheile den Farbstoff noch nicht abgegeben haben. Fasern, wie in Fig. 1 bei $a$ abgebildet, erhält man dann, wenn zufällig die äusserste Peripherie einer Zelle gerade angeschnitten wird oder weun, wie $R$ a b l hervorhebt, die Platten von Flügelyellen aus der zweiten Schicht der Epidermis auf dem Querschnitte getroffen werden.

Was die Intercellularbrücken angeht, so erstrecken sich diese zwisehen den Spiralfasern in ihrer ganzen Ausdehnung bis zur Kutis. Knötchenförmige Anschwellungen in der Mitte der Brücke waren stets mehr oder weniger deutlich nachweisbar. Wenn Herxheimer und Müller sie nicht beobachten konnten, so trägt die Schuld daran die Methode; bedient man sich zur Färbung des Eisenhämatoxylins, so sind sie stets bei sorgfältig darauf gerichteter Differenzirung als intensiv schwarze, meist spindelförmige Gebilde nachweisbar. Die Brtickenfasern konnte ich hier nicht weiter als bis zur Zelloberfläche verfolgen; die Intercellularräume reichen bis unmittelbar zur Kutis herab. Die Basalzelle ist bekanntlich in ihrem oberen Theile, wo sie den Kern in sich birgt, oval, unterbalb desselben zeigt sie eine deutliche Einschnürung and bildet dann nach unten einen abgestumpften Kegel, dessen Basis der Kutis aufsitzt; dementsprechend zeigen die am beiderseitigen Zellrande verlautenden Spiralfasern 
eine gegen die Mittellinie der Zelle gerichtete Einbuchtung unterhalb des Kerns, um dann wieder von einander zu divergiren; dabei erreichen sie mit ihrem Ende die Spiralfasern der Nacbbarzelle und grenzen so die Intercellularräume gegen die Kutis zu ab. Aus Fig. 1 wird dies deutlich. Entsprechend der Zellcontur erscheinen die Intercellularräume weiter oder enger, die Brücken länger oder kürzer, ohne dass sich in dem Aussehen ihrer medialen Anschwellung eine Aenderung nachweisen liesse.

Neben den Spiralfasern hat $\mathrm{Her} \times \mathrm{h}$ eimer (21) noch eigenthümliche $b$ ü schelf̈örmig angeordnete Fasern beschrieben, die er selbst für Protoplasmafasern hält. K roma y er (28) glaubt, dass diese Büschel in der Weise zu Stande kümen, dass die Protoplasmafasern benachbarter Zellen den Raum zwischen sich ausfüllen; die Büschel würden sich demnach aus verschiedenen Zellen zusammensetzen. Ich vermag dieser Anschauung nicht beizutreten. Die sog. Büschel liegen stets in dem als kegelformig beschriebenen Basaltheil der Zelle und werden durch die Spiralfasern von dem Intercellularraum abgegrenzt. Ein Theil der Büschelfasern setzt sich nach oben hin gegen die Spiralfasern zu fort und verlïuft mit diesen um den Kern berum, ein anderer hört kurz abgeschnitten unter diesem auf. Wie oben beschrieben, umgibt eine äusserst schmale Zone von Protoplasma den Kern, in deren Peripherie eben die Spiralfasern verlaufen; gegen die Kutis za breitet sich aber das Protoplasma nach einer deutlichen Einschnürung unmittelbar unterhalb des Kernes aus; die Fasern sind also in dem Kerntheil der Zelle auf eine enge Zone zusammengedrängt, in der Basis vermögen sie sich dagegen auszudehnen, sie s trah le ngewissermaassengegen die $\mathrm{K}$ u tis zu a $\mathbf{z}$; dabei bleiben die stärksten stets in der Peripherie des Protoplasmas, sie stellen die Spiralfasern dar, während die schwächeren die übrige Protoplasmamasse durchziehen. Durch dieses Ausstrahlen von der verengten Stelle her gegen die Kutis zu entsteht die Büschelform, jedes Büschel besteht also aus Fasern einer einzigen Zelle. Wäre $\mathrm{Kr}$ oma yer's Angabe richtig, so müssten zwischen den Büscheln selbst wieder Intercellularräume- und Brücken nachweisbar sein, das ist jedoch nie der Fall; nur an ihrem äussersten Ende nähern sich die Spiralfasern der benachbarten \%ellen und bilden so die Intercellnlar- 
räume von unten her begrenzend die Trennung des Epithels gegenüber der Kutis.

Alle Fasern einer Zelle und ebenso die ihrer Nachbarzellen reicheu gleich weit herab, so dass also die Epidermis gegen die Lederhaut durch eine gleichmässige Linie abgesetzt erscheint. Niemals lässt sich feststellen, dass die Fasern einer Epidermiszelle tiefer in die Kutis herabreichen, als die einer anderen. Färbt man die Schnitte, die mit Eisenhämatoxylin behandelt waren, mit Rubin nach, so erscheinen die Fasern der Epidermis schwarz oder dunkelbraun, die der Kutis roth (Fig. 1). Loeb (33) und Beneke (3) haben die Behauptung aufgestellt, dass Fasern der Epidermis direkt in solche rer Kutis übergeben sollen. Ein derartiges Verhalten konnte ich gleichfalls niemals konstatiren, die schwarzen Fasern hören vielmehr an einer bestimmten Grenze plötzlich auf, und die rothen fangen dort an; ein Zusammenhang, der sich doch dadurch charakterisiren misste, dass einmal die schwarze Färbung weiter herabreicht oder die rothe weiter hinauf, existirt also nicht. Dagegen sieht man deutlich Fasern aus der Kutis gegen den basalen Theil der Epidermiszelle zu ausstrahlen. Ueber ihr näheres Verhalten vermag ich mit Sicherheit nichts auszusagen, was ja hinreichend durch die ausserordentliche Feinheit der Gebilde auch bei den stärksten Vergrösserungen erklärlich ist. Es ist jedoch aus genetischen Gründen wahrscheinlich, dass ein Eindringen von Kutisfasern in das Protoplasma der Epidermiszelle selbst auszuschliessen ist. Vielmehr scheint die Verbindung beider Lagen durch Ineinandergreifen hergestellt zu sein and zwar derart, dass ebenso wie die Fasern der Epidermiszelle auch das uibrige Protoplasma gegen die Basis zu auseinanderweicht, das Protoplasma also gewissermassen ausgefranst ist. Zwischen diese ausgefransten Protoplasmaparthieen dringen nun die Fasern der Kutis ein, ohne aber in die Protoplasmafasern oder in das ubrige Protoplasma überzugehcn. Der Zusammenhalt beider Theile wird wahrscheinlich durch eine $\mathrm{K}$ itts ubstanz bewerkstelligt. ' Dass jedenfalls die Verbindung zwischen Kutis und Epidermis eine leicht lösliche ist, geht aus den Angaben von Philippson (38) und Loewy (34) hervor, nach denen schon eine $1 / 3-1 / 4 \%$ Essigsäurelösung, vielleicht jede organische- oder Mineralsäure, genügen soll, eine glatte Trennung herbeizuführen. Wie Rabl (42) treffend betont, 
macbt dieses Verhalten das Vorhandensein einer Kittsubstanz äusserst wahrscheinlich, schliesst dagegen einen Zusammenhang durch elastische Fasern, die sich nach den Angaben von Schütz (54) direkt in die Fasern der Epidermis fortsetzen sollen, mit Sicherheit aus.

Wenn ich nunmehr zu der Betrachtung der Zellen des eigentlichen Strat. Malp. übergehe, so habe ich mich über folgende Punkte zu äussern :

I. uber den Bau der Zelle,

II. $n \pi$ Verlauf der Portoplasmafasern,

III. " die Membran und die Intercellularstructur.

I. Durch die Entdeckung Ranvi er's (46), dass das Protoplasma der Zelle des Strat. Malp. einen fibrillären Bau zeige, ist die Aufmerksamkeit aller folgenden Beobachter mehr oder weniger auf die Art und den Verlauf dieser faserigen Structur gerichtet worden. So kam es, dass, trotzdem $R$ anvi er selbst noch von einem interfibrillären Protoplasma spricht, in den meisten Arbeiten ein Hinweis auf den Theil des Protoplasmas feblt, der neben den Fibrillen die Zelle ausmacht. Soweit ich die Literatur übersehe, war es U n na (61), der zum ersten Mal wieder die Aufmerksamkeit auf jenen zwischen den Fasern gelegenen Theil des Protoplasmas lenkte. Nach ihm würde sich das „Epithelprotoplasma" aus einem Spongioplasma und einem Granoplasma zusammensetzen. Das erstere soll eine homogene, durchsichtige und sehr schwer färbbare Masse sein, welche die Epithelfaserung und den Kern allseitig umhüllen und sich auch etwas auf die Intercellularbrücken fortsetzen soll, während das letztere in Hohlräumen der spongiösen Substanz als körniger Wandbelag oder als mehr oder weniger dicht gepresste Körner oder Bröckel seine Lage haben soll. Beide Substanzen sollen das eigentliche Substrat der Verhornung bilden. Neuerdings hat Herxheimer (22) gleicbfalls das Vorhandensein eines „Epithelprotoplasmas" beschrieben. Mit Hilfe einer Cresylechtviolettfärbung ist es ihm gelungen, einen netzförmigen Bau des Protoplasmas nachzuweisen, der also Unna's Spongioplasma entsprechen wirde, dagegen erklärt er die Körnelung $d$. h. das Granoplasma für eine pathologische oder postmortale Erscheinung. Ihm ist dieser netzförmige Bau ein Beweis dafür, dass das Protoplasma wabige Structur im Sinne Bil tschli's habe, die Netze wären nichts anderes 
als querdurchschnittene Wabenwände. Die erst aufgestellte Behauptung, dass die Protoplasmafasern durch Fixirung und Färbung sich als Fasern darstellende Wabenwände wären, hat er jedoch in einer späteren Mittheilung (23) auf Grund eines besseren Differenzirungsverfahrens zurückgenommen und lässt nun die Protoplasmafasern innerhalb der Wabenwände verlaufen. Ich habe mich zur Darstellung dieses Theiles des Protoplasmas der von Herxheimer angegebenen Methode bedient, ohne jedoch trotz genauer Befolgung der empfohlenen Fixirung und des Färbeverfahrens zu günstigen Resultaten zu kommen. In zwei Punkten bin ich allerdings von seinen Angaben abgewichen, einmal habe ich nicht in Celloidin, sondern in Paraffin eingebettet und dann habe ich nicht Schnitte von $8 \mu$, sondern von $2,5 \mu$ gemacht; trotzdem erhielt ich stets ein negatives Resultat. Bilder, wie sie Herxheimer in Fig. XII abbildet, habe ich zwar gelegentlich seben können, aber ich gestehe offen, dass ich nicht den Muth habe, auf Grund dieser absolut nicht specifisch erscheinenden Färbung eine Theorie über den Bau des Protoplasmas der Epidermiszellen aufzustellen. Das einzige; was ich mit dieser Methode finden kann, ist eine Bestätigung der Herx b eim er'schen Angaben, dass die Fasern, bes. auch die Intercellularbrücken, einen mehr bläulichen Ton haben gegenüber einem mehr röthlichen des übrigen Protoplasmas. Bei der Färbung mit Eisenhämatoxylin und Nachbehandlung mit Rubin gelingt es jedoch, genügend dünne Sclunitte soweit $z u$ differenziren, dass die Fasern dunkelbraun oder schwär\%lich hervortreten, während der übrige Zellbestandtheil roth gefürbt wird. Dieser Theil macht bald den Eindruck eines mebr granulirten, bald den eines mehr gerüstartigen Baues (Fig. 2), sodass ich nicht in der Lage bin, mich in dieser Hinsicht bestimmt zu äussern. Nur gegenüber der Annahme Herxheimer's, dass die Protoplasmafasern in den Wabenwänden verlaufen sollen, möchte ich betonen, dass die Fasern viel zu dick sind, als dass ein derartiger Verlanf in den nach der Herxheimer'schen Darstellung in der oben erwähnten Figur ausserordentlich schmalen Wabenwänden möglich wäre. Jedenfalls aber dürfen wir soviel als feststehend annehmen, dass die Zellen des.Str. Malp. neben den Fibrillen noch eine deutliche protoplasmatische Structur zeigen, über deren besonderen Bau bei den ungemein feinen Verhältnissen sich mit Sicherheit kaum etwas 
aussagen lässt. Durch die Weigert'sche Fibrinmethode, die nur die Fasern zur Anschauung bringt, ist dieser zweite Zelltheil, der, wie ich später auseinanderzusetzen babe, eine wesentliche Rolle in dem nekrobiotischen Process spielt, mehr in den Hintergrund gedrängt worden. Der Kürze wegen empfiehlt es sich, die Protoplasmafasern als Fibrillarstructur und den protoplasmatischen Rest als Interfibrillarstructur zu bezeichnen.

II. Von einem Ueberblick über die Geschichte der Protoplasmafaserung glaube ich absehen zu können. Das Verdienst, sie zuerst gesehen und beschrieben $z u$ baben, kommt jedenfalls Ranvier zu, während Kromayer (30) uns eine Methode gelehrt hat, die sie in besonderer Schärfe und Schönheit darzustellen ermöglicht. Ueber die Natur der Fasern sind die Ansichten noch getheilt; wäbrend Ranvier sie noch in seiner letzten Arbeit (47) für Differenzirungsproducte des Protoplasmas bält (élaborés par lui), ähnlich den Stärkekörnern der Pflanzenzelle, vertreten wobl jetzt die meisten Autoren, so bes. FI emming (16), Unna (60), Rabl (40), Kromayer (30) und Herxheimer (22) die Ansicht, dass sie echtes Protoplasma im K up f fer'schen Sinne wären. Was den Verlauf der Fasern angeht, so hat gegenuber der Annahme, das die F'asern die ganze Zelle gleichmässig durchsetzen, zuerst Beneke (3) die Behauptung aufgestellt, dass sie cuticulare, membranartige Bildungen seien; die nach ihm scheinbar das Protoplasma darstellenden Fibrillenzüge erklärt er als cuticular, indem er kurzweg den ganzen Zelleib bis zur nächsten Umgebung des Kernes zur Cuticula rechnet. Schütz (54) ist dieser Auffassung insofern beigetreten, als nach ihm die Fasern nur in der Rindenschicht des Protoplasmas, nicht aber im Innern der Zelle vorkommen sollen. Dagegen wendet sich Kromay er (31), indem er hervorhebt, dass bei dieken Schnitten nur die oberflächlichen Lagen gefärbt würden, die tiefern aber farblos bleiben. Herxheimer (22) will an Kromayer's eigenen Präparaten eine Bestätigung der Angaben von B en eke gefunden haben; an diesen soll gleichfalls die nächste Umgebung des Kerns von Fasern frèi erscheinen. Zur Beurtheilung dieser Frage ist, wie $\mathrm{K}$ romayer treffend hervorhebt, äusserste Dünne der Schnitte erstes Erforderniss, Schnitte von $10 \mu$, ja schon von $5 \mu$ sind dazu völlig ungeeignet. Ich habe in Fig. 3 einen Schnitt wiedergegeben, der $2,5 \mu$ dick und nach den Angaben Kromayer's gefärbt ist, in 
Fig. 4 einen von der gleichen Dicke mit Heidenhain'schem Eisenhämatoxylin mit nachfolgender Rubinfärbung behandelt.

Bei $a$ in Figur 3 ist die Zelle in ihrer Gesammtheit von Fasern durchzogen, die in verschiedenen Richtungen sich kreuzend, Netze untereinander bilden; die Fasern erstrecken sich bis zu der Kernhöhle, in welcher der geschrumpfte und ungefärbte Kern gelegen ist. Dabei fällt auf, dass die Faserung keine gleichmässige ist, insofern als man dickere und dünnere Fasern unterscheiden kann. Die Vertheilung dieser Fibrillen ist jedoch keine willkiurliche, sondern stets verlaufen die stärksten an der äussersten Peripherie der Zelle und $z$ war wiegt bei ihnen eine mehr parallele Anordnung vor. Ist die Zelle, wie bei $b$, in der Richtung des Faserverlaufs getroffen, so erscheinen sie als deutliche Zellconturen; ist sie dagegen senkrecht zur Verlaufsrichtung geschnitten, so ișt der Zellrand eingefasst von einer Reihe dicker Punkte, wie sie bei $c$ wiedergegeben sind. Es ist selbstverständlich, dass man gelegentlich auch Zellen sieht, in denen solche besonders dicken Fasern mitten durch den Zellleib zu verlaufen scheinen; die Zellen $d$ zeigen ein derartiges Verhalten. Jedoch sind dies nichts anderes als Oberflächenbilder, wie man daraus erkennt, dass bei geringem Heben des Tubus nun eine deutliche feine Punktirung erscheint, die Querschnitte der Intercellularbrücken. Niemals konnte ich an Zellen, die genau durch die Mitte getroffen waren, in denen man also eine grosse Kernböhle mit reichlichem Protoplasma in ihrer Umgebung und besonders an den Polen vor sich hatte, stärkere Fasern erkennen, die am äussersten Pol beginnend in der Mittellinie der Zellen gegen die Kernhöhle zu verlaufen wären, stets lagen solche Fibrillen nur in der äussersten Peripherie. Dass es sich dabei um ungleiche Differenzirung gehandelt hat, ist schon deswegen auszuschliessen, weil ja thatsächlich auch im Zellinnern feinere Fasern ebenfalls deutlich zu erkennen waren. Jedoch ist diese Anordnung nicht so $\mathrm{zu}$ verstehen, als ob beide Faserarten scharf von einander getrennt wären, im Gegentheil lässt sich stets ein inniger $\mathrm{Zu}$ sammenhang und Uebergang zwischen beiden nachweisen. Das Verhalten der Fasern findet man in derselben charakteristischen Weise wieder an Präparaten, die wie Figur 4 mit Eisenhämatoxylin behandelt sind; auch hier verlaufen die stärksten Fibrillen peripher, während sich im Zellinnern nur ein Netzwerk 
feinster Fasern zeigt. Ich habe diese Figur bes. auch deswegen wiedergegeben, um den zwischen den Fasern gelegenen Theil des Protoplasmas zur Anschauung zu bringen, der bei der $\mathrm{K}$ r 0 mayer'schen Methode sich nur durch einen leichten T'on gegentuber wirklichen Gewebslücken zu erkennen giebt. Was das Verhältniss zwischen Fibrillar- und Interfibrillarstructur angeht, so scheinen beide in Wechselbeziehung zu einander zu stehen. Während nämlich die interfibrilläre Substanz im periphersten Theil, also im Gebiet der starken, mehr parallel und dichter aneinander gelagerten Fibrillen in geringerer Stärke nachweisbar ist, wird sie gegen den Kern zu reichlicher in dem Maasse, als die Fasern an Kaliber abnehmen. Etwas Aehnliches hat jedenfalls Herxheimer (22) gesehen, wenn er angiebt, dass in der Zellperipherie seine Netze, in deren Wänden ja die Fibrillen verlaufen sollten, gröber seien und gegen das Centrum engmaschiger wiirden, $d . h$. das Material, aus dem sich die Interfibrillarstructur zusammen. setzt, ist spärlicher an der Peripherie, reicher gegen die Mitte der Zellen zu vorhanden.

Neben diesen Fasern baben Ranvier (45), Renaut (51) und Kromayer (30) ausserordentlich lange Fibrillen beschrieben, die sich 2, ja sogar 5 und noch mehr Zellen weit erstrecken und diese getrennt liegenden Zellen untereinander in Verbindung setzen sollen. Ich möchte schon hier erwähnen, dass es mir nicht gelang, mich von dem Vorbandensein solcher fortlaufenden Riesenfasern zu itberzeugen; bei der Besprechung der Intercellularstructur werde ich noch darauf zurick zukommen haben.

Auf Grund meiner Präparate glaube ich also über die Fibrillarstructur der Zelle des Strat. Malp. soviel aussagen zu können:

1) Die Zelle wird in ibrer ganzen Ausdehnung ron der äussersten Peripherie bis zur Kernhöble ron Faserndurchzogen;

2) die Fasern sind nicht alle ron gleichem Kaljber; weitaus diestärksten liegenan der Peripherie und amkreisen in mehr paralleler Anordnung die Zelle, während die feinerenim $Z$ ellinnerneindichtes $M$ aschenwerk bilden; 
3) zwischen beiden Fasersorten besteht ein $\mathrm{Z}$ us ammenhang und Uebergang;

4) dieim Gebietedesperipheren Theils mehr spärliche Interfibrillarstructur scheint gegendas Centrum der Zellean Masse zuz u n e h m e n.

Wenn anch Be neke (3) entschieden zu weit geht, indem er den grössten Theil des Zellleibes zur Cuticula schlägt, um so seine Ansicht zu begründen, dass die Fasern nur cuticulare Bildungen wären, so hat er doch insofern Recht, als er die starken Fasern, die er offenbar gesehen bat, für eine stärkere Differenzirung des peripheren Zellprotoplasmas hält. Von einer ausgesprochenen Membran zu sprechen, empfieblt sich für diese Bildung nicht, da damit doch immer der Gedanke an etwas Abtrennbares verbunden ist, oder doch an eine Structur, die einen noehr homogenen Charakter hat und mit dem Eingehüllten in keinem oder nur in lockerem Zusammenhang steht. Dies trifft aber nach der obigen Zusammenstellung hier nicht zu; es handelt sich vielmehr lediglich um eine stärkere Differenzirung des peripher gelegenen Protoplasmas. R e n a u (51), der aber eine specifische Metbode zur Darstellung der Fasern nicht verfügt, ist trotzdem dieser Unterschied innerhalb des Protoplasmas aufgefallen, er bezeichnet die periphere Zone als fibrillär mit besonderer Differenzirung der Oberfläche, während er in dem übrigen Zellleib keine besondere Structur wahrnahm; der ersteren, der $n^{\text {zone exo- }}$ plastique $^{u}$ stellt er die letztere als $n^{\text {zone endoplastique }}$ " gegenüber. Seinem Vorgange schliesst sich $S t \mathfrak{u} d \mathbf{n} \check{c} \mathbf{k a}(57)$ an und schlägt die Beibehaltung der Namen Exoplasma und Endoplasma für derartige Bildungen der Zellen vor, wobei er jedoch unter ersterer Bezeichnung auch noch abtrennbare Oberflächenschichten mit einzieht. Es dürfte sich vielleicht empfehlen, so lange noch deutliche Uebergänge zwischen peripherem und innerem Zellteil bestehen, von Exo- und Endoplasma zu sprechen; ist aber bereits eine Trennung eingetreten und hat die Differenzirung des peripheren Theils so zugenommen, dass er sich auch in seinem physiologischen Verhalten von dem übrigen Zellleib unterscheidet, die Bezeichnung „Zellmembran " zu wählen. Demgemäss verstehe ich weiterhin unter Exoplasmaden in der Zellperi- 
pheriegelegenen stärker differenzirten Theil der Z ellen des Strat. M al p.

III. Wenn ich nunmehr zu einer Besprechung der $\mathrm{Z}$ ell. m e mbran übergehe, so erscheint es zweckmässig, die I n t e rcellu larstru ctar gleich mit abzuhandeln, da beide Gebilde vielfach mit einander in Verbindung gebracht worden sind; unter Membran ist hier im Sinne der Autoren eine pelliculaartige Umhüllung der Zelle zu verstehen, die auch auf die Intercellularbrücken übergehen würde. Auch bei dieser Frage glaube ich von einem ausführlichen geschichtlichen Ueberblick absehen $\mathrm{zu}$ können. Von allen Seiten wird jetzt anerkannt, dass die Zellen des Str. Malp. durch Zwischenräıme von einander getrennt sind, in denen nach den Versuchen von Retzins und Key (52) Lymphe circulirt, welche der der Blutgefässe entbehrenden Epidermis die Ernährungsflüssigkeit zuführt; die Ansicht, dass es sich dabei jedoch um eine etwas anders geartete Flüssigkeit handeln soll, als man gewöhnlich unter Lymphe versteht, ist von Flemming (17) vertreten worden. Die Intercellularräume, auch dies erfreut sich allgemeiner Anerkennung, werden von Fasern durchzogen, die eine Zelle mit der anderen in Verbindung setzen. Ueber den Bau dieser Brücken gehen jedoch die Ansichten auseinander. Während Ranvier (45) glaubt, dass die Brticke aus einer Protoplasmafaser besteht, welche gewissermaassen als Scheide eine Fortsetzung der Interfibrillarsubstanz erhält, stellt Ram on y Cajal (43) nach Befunden an Lippencarcinomzellen die Behauptung auf, dass es sich bei dieser Scheidenbildung um die Fortsetzung einer die ganze Zelle einhüllenden Membran handle. Manille I d e (25) hält dagegen die ganze Faser, an der er Achse und Scheide nicht $z u$ unterscheiden vermag, für die "dépandance" einer reticulär gebauten Zellmembran, eine Ansicht, die übrigens viele Jahre früher schon von Biesiadecki (4) ausgesprochen warde. Nach Koelliker (26) lassen die tiefgelegenen Schichten des Strat. Malp. keine Membran erkennen; die Brücken sind also nach ihm hier Verlängerungen des Zellprotoplasmas. $\mathrm{K} \mathrm{r} 0$ ma y er (29) steht auf dem Standpunkt $R$ amon y Cajal's, insofern er annimmt, dass die Intercellularbrücken ans Protoplasma als Centrum und einer Fortsetzung des Zellmantels als Umkleidung besteht. Garten (18) begnught sich mit der Feststellung, dass die Brücken dicker seien als ihre Fortsetzung im Zellinnern 
und verweist zur Erklärung dafür auf die Angaben $R$ a n vier's und Ramon y Cajal's. R a bl (40) endlich schliesst sich gleichfalls diesen letzteren an, wonach die Bricke ausser der Fascr anch noch aus einem Mantel nicht differenzirten Protoplasmas bestehen soll.

Es würde sich demnach um folgende Fragen handeln:

I. Ist die Zelle des Strat. Malp., zunächst abgesehen von den Intercellularbrücken, von einer Membran umkleidet?

II. Bestehen die Intercellularbrücken nur aus einer einfachen Protoplasmafaser oder empfangen sie noch eine Umhüllung? Wenn letzteres der Fall, ist dieser Mantel

a) eine Fortsetzung der Interfibrillarstruetur oder

b) " $"$ einer deutlichen Zellmembran?

III. Enthält die Brïcke überhaupt keine Protoplasmafaser und ist sie nur der Ausläufer einer Zellmembran?

Bevor ich jedoch auf eine Erörterung dieser Fragen eingehe, muss ich noch jenes eigenthümlichen Gebildes Erwähnung thun, das als media le A n s chwellung der In tercellu. larbrucke zuerst von $\mathrm{Bi}$ z zozero (5) gesehen, die verschiedenste Deutung erfahren hat. Nach $R$ anvier (45) soll es ein elastisches Organ darstellen, das den Fasern der Zelle und so dieser selbst ermögliche, einem auf sie ausgeübten Zug Folge zu leisten; es würde demnach stets bei engen und nie bei weiten Intercellularräumen angetroffen werden. Nach $R a m o n ~ y$ Cajal (43) bandelt es sich um eine Anhäufung des die Brtickenfaser umschliessenden Protoplasmas; bei starkem Zug soll dieser Mantel, der ja an der Insertion der Brïcke in die Zellmembran übergehen würde, an dieser Anheftungsstelle abreissen und nach der Brückenmitte zurückfliessen; er kommt zu diesem Schlusse, weil er beobachtet haben will, dass die Anschwellung sich stets an weiten Intercellularräumen findet. Endlich hat $\mathrm{K}$ olos s ow (27) die Theorie aufgestellt, dass die Knötchen die bei Zug nicht verdünnte Stelle des Protoplasmas wäre, die in der Mitte am widerstandsfähigsten sei, während sie an den Enden sich ausziehe; er schliesst dies daraus, weil er gerade entgegensetzt von Ranvier die Anscliwellung stets nur an weiten Intercellularräumen gesehen haben will. R einke (50) und R a b l (40) balten sie 
für Gebilde, deren Bedeutung nur in der genetischen Seite licge; nach ersterem sind sie nichts anderes als die persistirenden Zwischenkörperchen F l e m m i n g's (15), nach letzterem wären sie eher mit den Strasburger'schen Dermatosomen identisch. Eine eigenthümliche Membranbildung will noch $R$ a b l (40) beobachtet haben; darnach sollen zwischen den Knötchen Verbindungslinien vorhanden sein, die nach ihm Querschnitte einer Membran wären, der demnach eine intercellulare Lage zukäme, derart, dass zwischen ihr und der zugehörigen Zelle ein von Flüssigkeit durchströmter Raum vorbanden wäre, den die Brücken durchsetzen würden.

I. Dass den Z ellen der tiefen Lage des Strat. Malp. e in e M e mbran zuko m t, d. h. also eine pelliculaartige Bildung, die nach aussen von dem als Exoplasma bezeichneten Zelltheil ihre Lage hätte, $\mathrm{muss}$ i c h in $\mathrm{Abrede}$ stellen. Die Möglichkeit, sie nachzuweisen, liegt einmal in ihrer färberischen Darstellung, dann aber, wenn wir noch mit K r o m a yer (29) annehmen, dass es sich dabei schon um eine beginnende Verhornung handelt, in ibrem Verhalten chemischen Reagentien gegenüber. Nun gelingt es aber thatsächlich mit keinem Färbemittel einen Saum um die Zellen der tiefen Lagen des Strat. Malp. zu erhalten. Ueberall bilden hier die starken Fibrillen eine periphere Abgrenzung gegenüber dem Intercellularraum, wie die Fig 1, 3 und 4 erkennen lassen. Diese Fibrillen selbst als Membran aufzufassen, ist nicht angängig, da sie, wie oben nachgewiesen, nur einen stärker differenzirten Theil des Zellprotoplasmas repräsentiren. Niemals lässt sich auch eine ihrem Bau nach der Interfibrillarsubstanz entsprechende Umhüllung der Zellen nachweisen (Fig. 4). Ebensowenig wie die färberische Darstellung ergab die mittels chemischer Reagentien ein positives Resultat. Wie schon K oelliker (26) hervorgehoben hat, lässt weder eine Behandlung mit Essigsäure noch mit Alkalien eine Membran in den tieferen Lagen herrortreten. Demgegenüber glaubt allerdings Kromayer (29) gesehen $z u$ haben, dass bei Verdauungsversuchen die Zellen des Strat. Malp. von einem weniger leicht rerdaulichen Mantel umgeben seien. Thatsächlich löst sich bei derartigen Versuchen in den tiefen Theilen des Strat. Malp. bald die ganze Zelle auf, während in den der Hornschicht genäherten Lagen eine periphere Zone längere Zeit dem Verdauungsprocesse Widerstand leistet. 
Diese Zone ist aber nichts anderes als das Exoplasma der Zelle, das als stark fibrillär differenzirter Theil gegenüber der PepsinSalzsäurelösung eben widerstandsfähiger ist. Die oben unter I gestellte Frage ist also zu verneinen.

II. Interessant ist nun, dass die meisten Autoren eine membranöse Umhüllung der Zelle selbst überhaupt nicht direct gesehen haben, sondern nur eine solche der Intercellularbrücke; das Vorhandensein dieser letzteren wurde jedoch auch nur wieder mehr indirect bewiesen, dadurch nämlich, dass die Intercellularbrücken dicker sein sollen als derjenige Theil ihrer Faser, der sich in den Zellleib fortsetzt. Man schloss aus dieser Beobachtung, dass der Faser nach ihrem Austritt aus der Zelle eine membranöse Umbüllung zukommen müsse, die ihrerseits doch nur wieder eine Fortsetzung einer die Zelle selbst umschliessenden Membran sein konnte. Eine genaue Beobachtung der Intercellularbricken ergiebt jedoch, dass diese Annahme auf einem Irrthum beruht. Zur Beurtheilung dieser Frage eignen sich bes. die mit Eisenhämatoxylin behandelten Schnitte wie Fig. 4. An der Brücke laben wir nämlich zwei (bezw. 3) Abscbnitte \%u unterscheiden, einen mittleren, die von Ranvier beschriebene Anschwellung und einen äusseren, doppelt vorhandenen, nämlich den von diesem Knötchen zur Zellperipherie führenden Theil. Der mittlere, das Knötchen, ist aufgetrieben, spindelförmig und läuft gegen die Pole $\mathrm{zu}$ aus (Fig. 4 und 5), sodass ein grosser Theil der Brücke auf diesen Abschnitt fällt; der darauffolgende, zwischen dem Ende des Knötchens und der Zellperipherie gelegene Theil ist sehr kurz und äusserst fein. Durch Färbungsmethoden, die die Knötchen und ihr allmähliches Abschwellen nicht scharf differenzirt erscheinen lassen, tritt der Unterschied der verschiedenen Strecken der Brücke im Kaliber nicht deutlich genug hervor, er wird aber ausserordentlich scharf nach Behandlung mit Eisenhämatoxylin, da die Knötchen sich bes. intensiv schwärzen und den Farbstoff lange festhalten. Die Verwischung des Unterschiedes begünstigen dann wesentlich auch dickere Schnitte, in denen mehrere Intercellularbrücken übereinander in den Schnitt fallen. Beides, Färbeverfahren und Schnittdicke, kann also ein gröberes Kaliber der ganzen Brücke vortäuschen und ihre Feinheit an der Zellgrenze verdecken. Zur Entscheidung der Frage, ob also der Brücke wirklich ein grösserer Dickendurchmesser zukommt als ihrer 
Fortsetzung in's Zellinnere, lassen sich demnach nur sehr feine und gut differenzirte Schnitte verwenden. An solchen sieht man

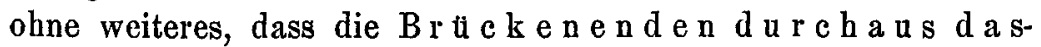
selbe Kaliber haben, wie ihre Fortsetzang in $\mathrm{nerhalb}$ der $\mathrm{Z}$ ell e; ferner kann man constatiren, dass die Brücke sich färberisch genau so verhält, wie die Zellfibrillen, als deren Verlängerung sie erscheint, eine $U \mathrm{~m} h$ ü $l \mathrm{I} u \mathrm{n} g \mathrm{durch}$ Interfibrillarsubstanz lässt sich nicht nachw.e i s e $n$; ausserdem haben sämmtliche Brücken ziemlich gleiches Kaliber. Was das Vorkommen der Knötchen betrifft, so findet man sie sowohl an Stellen mit weiten als auch mit engen Intercellularräumen, sodass die verschiedene Deutung, die ihnen $\mathrm{R}$ a n vier, $\mathrm{R}$ a mon y $\mathrm{Caj}$ a $\mathrm{l}$ und $\mathrm{K}$ ol o s s ow gegeben haben, wohl keine Berechtignng haben. Ich möchte mich in dieser Frage $\mathrm{Re}$ in $\mathrm{ke}$ und $\mathrm{Rabl}$ anschliessen, welche die Knötchen als eine aus der Zeit der Zellteilung persistirende Bildung betrachten, eine Annahme, die noch weiter durch ihr Verbalten in den peripheren Schichten der Epidermis, worauf unten zurückzukommen sein wird, eine Bestärkung erfährt. $\mathrm{Ob}$ wir in ihnen Zwischenkörperchen oder Dermatosomen zu sehen habel, lässt sich nur durch Untersuchung von Zellen während der Mitose entscheiden.

Eine Verbindungslinie zwischen den Knötchen zu sehen, wie sie $R$ abl beschrieben, ist mir niemals gelungen; bei dickeren Schnitten können tiefer gelegene und zwischen den oberen durchscheinende Knötchen eine derartige Linie wohl vortäuschen; möglicherweise handelt es sich dabei auch um eine vorübergehende Bildung junger Zellen, da Rabl sie besonders am Epithelcarcinomen gesehen hat. Würde hier eine Membranbildung, wie Rabl glaubt, vorliegen, so müsste man zunächst nachweisen, wie eine solche sich gegenüber der Membran verhält, die doch auch die Brücke selbst umschliessen und sich von da auf die Zellperipherie fortsetzen soll; man käme dann zu der Annahme zweier Membranen für die gleiche Zelle, einer diese unmittelbar umschliessende, die auf die Brücke uberginge, und eine intercellulare, die an den Knötchen sich mit ersterer vereinigen würde. Die Nothwendigkeit dieser Annahme spricht nicht besonders für eine Deutung der von Rabl gesehenen Verbindungslinie in seinem Sinne. 
Die Thatsache, dass alle Brücken das gleiche Kaliber haben, besonders aber der Umstand, dass $\mathrm{j}$ e d e Faser, die einen Intercellularraum durchzieht, in dessen Mitte ein Knötchen trägt, schliesst das Vorhandensein besonders starker isolirter Fibrillen, die sich über mehrere Zellen erstreckenen sollen, mit ziemlicher Sicherheit aus.

Frage II wäre also dahin zu beantworten, dass die Brücke nur aus einer Protoplasmafaser mit einer medialen spindelförmigen Anschwellung besteht; sie empfängt keine weitere Umbüllung weder von der Interfibrillarsubstanz noch von einer Zellmembran.

III. Was nun noch zuletzt die Ansicht Manille Ides betrifft, dass die $\mathrm{Br}$ ü cken $n$ u r ein e Verlä̈nger ung einer reticulären $\mathrm{Ze} 1 \mathrm{~lm}$ e m b a $\mathrm{n}$ vorstellen sollen, so ist diese Aufstellung, wie aus dem Vorhergehenden folgt, $u n b a \mid t b a r$, ganz abgesehen davon, dass sich niemals an den Zellen des Strat. Malp., was bereits Koelliker und Rabl betont haben und auch ich bestätigen kann, ein netzförmiger Bau der Oberfläche nachweisen lässt. Damit ist auch Punkt III der Frage erledigt.

Fassen wir nun kurz die Resultate uber den Bau der Zellen des Strat. Malp. zusammen, so lässt sich darüber folgendes sagen:

1. die Zellen besteben a useiner Fibrillarsubstanz, die an der Peripherie ihre höchste Differenzirung erfährt, dem Exoplasma, und einer interfibrillären Masse, die ihregrösste Anhäufung mehr am den Zellkernhat, dem Endoplasma;

2. die Intercellularbrücken sind Fortsetzungender Fibrillendes Zellinnern; die spindelförmige Ansehwellung in ibrer Mittefindetsich stets und hat wobl nurgenetische Bedeatung;

3. isolirte Fibrillen, die entfernter gelegene Zellen unter einander in Verbindung setzen sollen, lassen sich nicht $\mathrm{n}$ ach weisen;

4. ein e membranöse Umkleidung der Zellen und der Brücenfasern ist nicht vorh anden;

5. die Zellender Basalsebicht unterschei- 
densich ron denen der höheren Lagen nurdurch ihrencylindrischen Bau und ihre basale Auffaserung; ihre Spiralfasern entsprechen den Fibrillen des Exoplasmasderletztern.

\section{Stratum granulosum.}

Die Zellen des Strat. granul. unterscheiden sich von denen des Strat. Malp. wesentlich in ihrer Form dadurch, dass diese ihren mehr isodiametrischen Charakter aufgeben und stark in die Länge gezogene Gebilde mit verkürztem Dickendurchmesser aus ihnen entstehen. Diese Gestaltveränderung ist eine allmähliche; die am stärksten abgeplatteten Zellen finden sich an der Grenze des Strat. corneum. Die Ursache des Formwechsels liegt bekanntlich in dem starken Oberflächendrusk und dem durch die Hautspannung bedingten $\mathrm{Zug}$, der sich um so bemerkbarer macht, je mehr die Zelle sich der Oberfläche nähert.

Das Strat. granul. ist aber besonders dadurch charakterisirt, dass in seinen Zellen eigenthümliche Körnchen auftreten, die Aufhammer (1) und Langerhans (32) zuerst gesehen und von Waldeyer (65) ihres Verbaltens chemischen Reagentien gegenüber als Keratohyalin bezeichnet wurden. In Betreff der Höhe, in der diese Granula zuerst auftreten, lässt sich keine bestimmte Angabe machen; in dem intrapapillären Theil finden sich Zellen, in denen es schon in ziemlich tiefer Lage nachweisbar ist; im allgemeinen machen jedoch die Keratohyalin führenden Zellen an der Haut von Vola manus und Planta pedis 4-5 Reihen aus, sodass die Angabe $\mathrm{Un} n \mathrm{a}$ 's (59), der nur 1-2 Lagen als normal bezeichnet, nur für die völlig vollgepropften Zellen zutrifft.

Während die körnige Natur des Keratohyalins kaum mehr von jemand geleugnet wird, ist die $\mathrm{Frage} \mathrm{nach}$ seiner H e r k u f t noch eine strittige; die darüber aufgestellten Theorien lassen sich folgendermassen zusammenfassen:

1. das Keratohyalin stammt aus dem Zellkern und zwar ist es:

a) ein Zerfallsprodukt des ganzen Kerns (ohne nähere Angabe der Substanz) - Me rts ching (36), Posn e r (39), S e l b or s t (55); 
b) des Chromatins - d'Urs o (64), Ernst (13), Tett e $\mathrm{n} \mathrm{h} \mathrm{a} \mathrm{m} \mathrm{m} \mathrm{e} \mathrm{r} \mathrm{(58);}$

c) ein Umwandlungsprodukt eines nicht näher bekannten Kernbestandtheils - R a b I (40).

2. Das Keratohyalin ist ein Zerfallsprodukt der Protoplasmafasern - Krom a y e r $(29,30)$.

3. Bei der Bildung des Keratohyalins ist neben dem Kern auch das Zellprotoplasma betheiligt - Rosenstadt (53).

Die unter $1 \mathrm{a} \mathrm{u.b}$ angeführten Autoren stützen sich im wesentlichen bei ihrer Annahme darauf, dass sie beobachtet haben wollen, dass das Auftreten des Keratohyalins mit dem Schwundedes Kernsgleichen Schritt baltc.

Es hat bereits $R$ abl auf die Oncorrectheit dieser Beobachtung hingewiesen; thatsächlich haben beide Vorgänge zeitlich absolut nichts miteinander zu thun. Man findet Zellen, die vollgepropft sind mit Keratohyalin, dabei aber an dem Kern kaum eine Spur von Zerfallserscheinungen erkennen lassen; noch gut erhaltene Kerne in der untersten Lage des Strat. lucidum sind sogar ziemlich bäufig. Namentlich war es aber auch die gleiche Färbbarkeit der chromatischen Substanz und des Keratohyalins, die die Annahme eines Zusammenhangs beider begiinstigte. Es ist selbstrerständlich, dass das gleiche Verhalten Farbstoffen gegenüber nie in diesem Sinne gedeutet werden kann. Dasselbe Argument hat ja gerade im vorliegenden Falle Kromayer als Beweis für die Bildung des Keratohyalins aus den Protoplasmafasern angeführt, ganz abgesehen davon, dass es gelingt, durch geeignete Behandlung das Keratohyalin zu lösen und nun färberisch nicht mehr zur Darstellung zu bringen, während das Chromatin ungelöst bleibt und seine Affinität zum Farbstoff behält. Als weiteren Beweispunkt für eine Entstehung aus dem Kern hat Merts ching die Thatsache herangezogen, dass das Keratohyalin nie im Intercellularraum a ftrete, und andere Autoren sind ihm darin gefolgt. Dass es niemals zwischen zwei Zellen weder. in den Intercellularlïcken noch in den Brücken auftritt, steht fest; aber im Mertsching'schen Sinne lässt sich dies kaum verwenden. Man kann höchstens daraus schliessen, dass bei der Bildung jedenfalls die Britcke unbetheiligt ist; niemals aber kann die obige Thatsache als ein Beweis für die Entstehung aus dem Kern gelten, eher spricht 
sie sogar dagegen; denn gelangt das Keratohyalin durch Auswandern aus dem Kern in das Zellprotoplasma, so ist nicht ein. zusehen, warum es nicht ebenso gut auch in die Brücken vorrücken soll. Warum dieser Theil frei bleibt, werde ich unten auseinanderzusetzen haben.

Ernst and Mertsching haben ferner das erste Auftreten des Keratohyalins in der Umgebung des Kerns als Beweis für ihre Theorie herangezogen und dieser Punkt ist es auch, den $R$ a bl acceptirt, und den er; wie er sagt, zum nAusgangspunkt fernerer Erwägungen ${ }^{\prime}$ nimmt. $\mathrm{Da}$ er jedoch sich überzeugen konnte, dass die färbbaren Kernbestandtheile in keinerlei Beziehung zu dem Keratohyalin stehen, kam er hauptsächlich durch Untersuchungen der Haut des Hühnerembryos und des Präputiums zu dem Resultat, dass es ein nicht färbbarer Kernbestandtheil sein mulsse, der sich „bald schon im Kerninnern, bald erst nach seinem Austritt in das Zellprotoplasma" zu Keratohyalin umwandle. Mit dieser Theorie kann aber $\mathrm{R}$ a bl ebensowenig die Thatsache erklären, dass, wie er ja selbst auch ausdrücklich gegen Ernst und Mertsehing betont, sich zahlreiche Zellen vollgepropft von Keratohyalinkörnchen finden ohne jede nachweisbare Veränderung des Kerns; denn auch der Austritt eines nunfärbbaren, noch nicht näher bekannten Kernbestandtheils“ müsste doch eine wesentliche Verringerung des Kernvolumens bedingen. Auch bleibt unit der $\mathrm{Rabl}$ a seben Annahme unerklärt, woher der doch absterbende Kern das Material nimmt, um die im Verhältniss zu seinen Volumen riesig grosse Keratohyalinmasse bilden zu können. E r n s t hat gegen diesen äusserst goewichtigen Einwand geltend gemacht, dass auch degenerirende Kerne Stoffe aus der Umgebung aufnehmen und sie umgebildet wieder ausscheiden könnten; $R$ a b I hat jedoch selbst diese nicht bewiesene Annabme ais zu complicirt mit Recht verworfen. Aber auch aus dem Grunde vermag ich $R$ abl's Theorie nicht beizutreten, weil ich ibre Voraussetzang nicht durchweg bestätigt finde, dass nämlich die ersten Keratohyalin-Körnchen stets nur in der nächsten Umgebung des Kerns anzutreffen seien. Das Auftreten des Keratohyalins findet bekanntlich in der Weise statt, dass sich zuerst feine Körnchen vereinzelt in dem Zellprotoplasma zeigen. Es gelingt mit Anwendung der Eisenhämatoxylinfärbung bei entsprechender Differenzirung diese kleinen Gra- 
nula ausserordentlich scharf zur Darstellung zu bringen; dabei beobachtet man, dass die Körnchenkeineswegs stets zuerst am Rande der Kernhöhle sich zeigen, sondern auch sehr oft mitten im Zellprotoplasma gegen d i e Pole h in (Fig. 6). Würde thatsächlich eine Auswanderung aus dem Kern stattfinden, so müsste es doch gelingen, gelegentlich auch die Granula auf diesem Wege zur Darstellung zu bringen. Keiner der Autoren hat dies aber beim Menschen mit Sicherheit beobachten können und auch mir selbst ist es nie geglïckt, Keratohyalin im Kern oder auf der Grenze zwischen diesem und dem Zellprotoplasma nachzuweisen; ein derartiges Verhalten müsste doch, wenn die Theorie richtig wäre, recht läufig anzutreffen sein; denn es müssten stets bis zur völligen Vollpropfung der Zelle Körnchen aus dem Kerne auswandern. Wie anders sollte man sich denn sonst das Wachsthum der Körner erklären? Die kleinen Granula werden gegen das Strat. lucid. zu groben Schollen, der Stoffzuwachs müsste also stets vom Kerne nachgeschoben werden. Dies kommt aber im mikroskopischen Bilde nicht zum Ausdruck, die Vergrösserung geschieht nicht in etwa concentrischen Zonen um den Kern herum, sondern grüssere und kleinere Granula sind völlig planlos in der Zelle zerstreut.

Nach all dem erklärt also die Annahme, dass das Ker atoly yalin ein Zerfallsproduct irgendeines Kernbestandstheils sei, niemals folgende Thatsachen:

1. die Erfüllung der ganzen Zelle mit Keratohyalin bei intactem Kern;

2. die Grössenzunabme dereinzelnen Gra$\mathrm{nula}$

3. das bedeutende Ueberwiegen des Keratohyalins an Masse über die Kernsub stanz;

4. das Freibleiben der Intercellularbrücken und der aussersten Zellperipherie; diese letztere Thatsache wurde gleichfalls von den meisten Autoren beobachtet.

Alle diese Momente machen es nothwendig, dem $\mathrm{Kern}$ als die Bildungsstäte des Keratobyalins a uf zugeben und diese in dem Zellprotoplasma selbst zu suchen. Thatsächlich ist auch Rosenstadt schon dahin geArchiv f. mikrosk. Anat. Bd, 56 
kommen, in letaterem einen wesentlichen Factor der Keratohyalinbildung zu sehen, wenn er auch auf Grund von Untersuchungen am Epitrichium des Hühnchens eine Mitbetheiligung des Kerns für wahrscheinlich hält, letzteres deswegen, weil er innerhalb des Kerns Keratohyalinschollen angetroffen hat; jedenfalls ist aber ein derartiges Verhalten beim Menschen noch nie mit Sicherheit beobachtet wordeu, somit besteht auch kein zwingender Grund hier noch den Kern als die Bildungsstïtte mit anzunehmen.

$\mathrm{Kr} \circ \mathrm{mayer}$ ist der Ansicht, dass das $\mathrm{Ker}$ a t o hy a linein Zerfallsproduct seiner Protoplasmaf a s e r sei; er kam zu dieser Annahme, weil mit seinem Färbeverfahren sich das Keratohyalin ebenso deutlich färbte als die Fibrillen innerhalb der Zellen, vor allem aber deswegen, weil er beobachtet haben wollte, dass Fasern innerhalb der Zellen des Strat. granul. gar nicht oder nur sehr spärlich vorhanden waren. Dagegen haben sich Unna (60), E r nst (14) und R a b l (41) gewandt, indem sie nachweisen konnten, dass die Protoplasmafasern innerhalb des Strat. granul. nicht zn Grunde gehen, sondern neben dem Keratohyalin deutlich erbalten bleiben; späterhin hat sich auch Kromayer (31) selbst von der Richtigkeit dieser Beobachtung tiberzeugen können und das Vorhandensein der Fasern nur noch für die Haut von Vola manus und Planta pedis in Abrede gestellt. $\mathrm{R} \mathrm{abl}$ ist es jedoch gelungen, sie auch hier mit Sicherheit nachzuweisen; icb selbst kann die Angaben U n n a und $\mathrm{R}$ abl's vollauf bestätigen. Wenn man mit den gewöhnlichen Fixirungsmitteln, Alkohol oder Formol, bärtet und dann nach K r o m a y e r fürbt, so nimmt das Strat. gran. einen gleichmässigen dunkelblauen Ton an, in dem Fasern and Granula nicht zu unterscheiden sind; differenzirt man länger, so geben die Fasern bald ihre Farbe ab, während sie die Keratohyalinschollen noch festhalten; man sieht dann nur Körner und keine Fasern; bei dünnen Schnitten und im geeigneten Moment abgebrochener Differenzirung gelingt es hie und da Bilder zu erbalten, wie sie $\mathrm{Rabl}$ abgebildet hat. Völlig überzengend sind aber auch diese nicht; man müsste das Keratohyalin in Lösung briugen oder doch so verändern, dass es die Affinität zum Farbstoff verlirt und dann nach $\mathrm{Kr}$ o m a y er färben; zeigen sich dann noch Fasern innerhalb der Zellen des Strat. gran., dann kann das Keratobyalin unmöglich ibr Zerfallsproduct sein. Ein derartiges 
Mittel ist die Z e n k e r'sche Flüssigkeit. Welcher Bestandtheil es ist, der die Lösung des Keratohyalins bewirkt, vermag ich nicht mit Bestimmtheit anzugeben; wahrscheinlich ist es jedoch der Eisessig, für den $\mathrm{W}$ a l d e y e $r$ (65) nachgewiesen hat, dass nach längerem Einwirken die Körner abblassen und einer stärkeren Quellung unterliegen. Jedenfalls lässt sich an Hautstückchen, die 24 Stunden in Ze nker'scher Flüssigkeit fixirt waren, kein Keratohyalin mehr weder mit dem K r o m a y er'schen noch mit dem Heidenbain'schen Färbeverfahren oder nur noch kleinere Bröckel, wie in Fig. 7, nachweisen. Statt dessen sieht man nun in den Zellen ein wirres Netz von Fasern, die ihrer Lage und Anordnung nach genau den Fasern innerhalb der Zellen des Strat. Malp. entsprechen. In Fig. 8 sind zwei solcher Zellen abgebildet; sie lagen unmittelbar dem Strat. lucid. an, entstammen also der obersten Zellreihe des Strat. granul. und erscheinen durch die Fixirung gequollen; der Kern ist in beiden noch gut erhalten. Auch in Fig. 7 lässt sich in den Zellen aus der gleichen Lage derselbe faserige Bau nachweisen wie in denen des Strat. Malp., die Fig. 5 aus demselben Schnitt wiedergibt. Damit ist also bewiesen, dass die Protoplasmafasern innerhalb des Strat. gran. persistiren, das Keratohyalin demnach auch nicht ihr Zerfallsproduct sein kann.

So kommt man schon per exclusionem auf den einzig noch übrig bleibenden Zellbestandtheil, die In ter fibrilla r mas se. Wenn das Keratohyalin wirklich ein Umwandlungsproduct dieses Zelltheils ist, so muss nachgewiesen werden einmal, dass ihrer Lage nach sich beide Substanzen entsprechen, und zweitens dass in dem Maasse als das Keratohyalin zunimmt, die interfibrilläre Substanz verschwindet. Der erste Beweis ist unschwer zu erlringen. In den Zellen des Strat. Malp. ist die fibrillare und interfibrilläre Substanz so vertheilt, dass erstere eine verdichtete periphere Zone, das Exoplasma, bildet und ausscbliesslich auch die Intercellularbrücke aufbaut, während die letztere den übrigen Theil des Zellleibs einnimmt, soweit er nicht von der ja auch hier vorhandenen Faserung in Anspruch genommen wird. Dem entspricht das Verhalten des Keratohyalins, das nie in den Intercellularbrücken auftritt und ebenso die Zellperipherie freilässt; die allerdings auch im Exoplasma noch etwas vorhandene Interfibrillarsubstanz kann sich bier nicht zu Keratohyalin umbilden, 
weil sich hier anders geartete Vorgänge abspielen, auf die weiter unten zurückzukommen sein wird. Die zweite Frage bereitet etwas mehr Schwierigkeiten, weil eben dort, wo die KeratohyalinSchollen liegen, das darunter befindliche Gewebe nicht zu erkennen ist. Bei Lösung der Granula sieht man dagregen mit der K r o ma y e r'schen Färbung (Fig. 8), dass der schon oben charakterisirte Ton, der das Vorhandensein eines weiteren Zellbestandtheils andeutet, fehlt; bei Behandlung mit anderen Farbstoffen, besonders mit Rubin, kann man jedoch constatiren, dass stellenweise Lücken in den Zellen vorhanden sind, oder die Interfibrillarsubstanz einen mehr körnigen Charakter angenommen hat. Differenzirt man Schnitte, die mit Eisenhämatoxylin behandelt waren, soweit, dass nur die Keratobyalingranula grefärbt bleiben, die Fasern aber alle ihren Farbstoff abgeben, so tritt bei Nachbehandlung mit Rubin die interfibrilläre Zellstruktur deutlicher hervor. In Fig. 9 ist eine derartige Zelle wiedergegeben. Man erkennt hier, dass vorwiegend in der nächsten Umgebung grösserer Granula die Interfibrillarsubstanz völlig fehlt, wählrend sie sich an anderen Stellen zwischen den Körnerm noch gut erhalten hat. Darnach ist der Schluss berechtigt, dass die Interfibrillarmasse, die ja doch gleichfalls bei dem sich in den peripheren Zellen abspielenden nekrobiotischen Prozess betheiligt ist, körnig zerfällt. Dieser Zerfall findet in der Weise statt, dass erst kleine Bezirke innerbalb des ganzen Zellleibes, vielleicht etwas mehr in der Umgebung des Kerns, da hier ja die stärkste Ansammlung der Interfibrillarsubstanz vorhanden ist, der Degeneration unterliegen; indem sich in der Nachbarschaft der gleiche Prozess abspielt, verschmelzen die gebildeten Körner untereinander; dadurch wachsen die Granula, bis schliesslich die ganze Grundsubstanz zerfallen ist. Dass die Schollen, auch wenn die ganze Zelle damit vollgepfropft ist, noch von einander getrennt bleiben und nicht eine compacte Masse bilden, hat seinen Grund darin, dass die Fibrillarsubstanz erhalten bleibt und so eine Art Hinderniss für die Vereinigung des in ihren Maschen gelegenen Keratohyalins bildet. A u a 11 diesen Gritnden er scheint es sicher, dassdas Keratobyalin wirklich das Zerfallsprodukt der Interfibrillarsubstanz vorstellt. Sonurerklärensich a ch ungezw angen alle Erseheinungenseines Auf. 
tretens, das Erfülltsein der Zelle bei intak tem Kern, die Volumenzunahme der Körner unabhängig von diesem letztern, die grosse Masse des Keratohyalins und endlich das Freibleiben der Brücken und der Zell peripherie.

Gegen diese Herleitung hat Herxheimer (22), ohne dass sie schon von irgend einer Seite aufgestellt worden wäre, Einwände erhoben, die aber nichts weniger als stichhaltig sind. Er fand, dass die Keratohyalinkörner unregelmässig in einem Netzwerk gelagert seien, und konnte stellenweise erkennen, dass in körnerfreien Zelltheilen auch kein Netzwerk vorhanden war - unter Netzwerk versteht er die Interfibrillarsubstanz - ; trotzdem glaubt er nicht, dass die Körner aus dem Netzwerk entstïnden und zwar weil beide gleichzeitig nebeneinander vorkommen. Das ist jedoch aus dem Grunde kein Gegenbeweis, weil ja das Keratohyalin allmählich sich bildet, das Netzwerk also in gleichem Mausse zerfallen muss; wo letzteres noch besteht, da ist eben noch kein Keratohyalin gebildet. Ebensowenig beweisend ist Herxheimer's zweites Argument. Er sagt: ${ }_{n}$ Wir können uns bein $\mathrm{krank}$ hafte $\mathrm{n}$ Zerfall des Netzwerks davon überzeugen, dass dessen Produkt durchaus unregelmässig gestaltete Theilchen sind; die Keratohyalinkörner sind zwar auch nicht regelmässig geformt, bilden aber doch nicht so zahlreiche. Varietäten der Form." Ausserdem sollen beim krankhaften Zerfall die körnigen Produkte kleiner und an Zahl grösser sein als die Keratohyalingranula. Es ist nicht einzusehen, warum deswegen, weil bei pathologischen Zuständen das Zerfallsprodukt weniger polymorph, zahlreicher und feinkörniger ist, der normale Vorgang ebenso geartet sein muss. Wegen der Verschiedenheit ist ja vielleicht gerade jenes von $\mathrm{H}$ er $\mathbf{x h}$ e imer skizzirte Produkt ein pathologisches! Ich möchte sogar die Beobachtung, dass a uch bei krankhaften Prozessen die Interfibrillarmassedie Neigung zum körnigen Zerfall h a t, wie beim normalen Vorgang, eher als einen Beweis für meine Annahme in Anspruch nehmen; anch dass im normalen Falle die Körner grösser und wenig zahlreich sind, im pathologischen dagegen feinkörniger und an Zahl bedeutender, spricht dafür, dass die Substanz, aus der sie beidemale entsteben, an M asse gle i ch is t. Dass übrigens das Netzwerk, d. h. die Interfibril- 
larsubstanz, gegen die Hornschicht zu schwindet, gibt He r x h e i m e r selbst zu. So sind seine sämmtlichen Einwände wenig beweiskräftig; eher können sie sogar noch als Beweis für dic Entstehung des Keratohyalins aus der Interfibrillarmasse mit angesehen werden.

Während diese Veränderungen an dem interfibrillären Theil des Protoplasmas vor sich gehen, bleibt der im Zellraum gelegene Theil der Fibrillarmasse erbalten, indem er ein vielleicht etwas mehr lockeres Netzwerk bildet (Fig. 8). Dagegen vollziehen sich im Exoplasma die bereits angedeuteten Umwandlungen. Die oberflächlichen starken Fibrillen beginnen sich fest aneinanderzulegen und zeigen die Neigung mit einander zu verschmelzen. Fig. 8 lässt diesen Vorgang deutlich erkennen; ebenso ist er in Figur $7 \mathrm{zu}$ beobachten. Letzteres Präparat stammt von der Katzenpfote; hier imponirt die verdichtete periphere Zone schon als ein dentlich rothgefärbter Saum; d. h. die das Exoplasma charakterisirenden Fibrillen der Zellen des Strat. Malp. verschmelzen innerhalb des Strat. granul. $\mathrm{zu}$ e in er Z ellmembran. Dieser Vorgang erklärt nun auch die Thatsache, warum das Keratohyalin diese Zone freilässt, weil eben der Verschmelzungsprozess die zwischen den Fibrillen gelegene, äusserst spärliche Fibrillarsubstanz mit einzieht. Der Nachweis einer Membran an den Zellen des Str. gran. ist bereits von Behn (2) und Kromayer (29) geliefert worden; letzterer Autor konnte sie durch Behandlung mit Säuren darstellen; nur verhalten sie sich Verdauungsflussigkeiten gegentiber weniger widerstandsfähig, wie die fertigen Hornzellen. Mit der Bildung einer Membran unterliegt auch die Intercellularstructur eigenthümlichen Veränderungen. Hier ist in erster Linie die Verengerung der Intercellularräume auffallend, die bereits von Koelliker (26) constatirt wurde. Ein Vergleich der beiden Fig. 5 und 7; die demselben Schnitte entstammen und bei gleicher Vergrösserung gezeichnet sind, ergiebt dies ohne weiteres. In Fig. 8 sind die Intercellularräume überhaupt nicht mehr nachweisbar; in Wirklichkeit ist die Verengerung jedoch keine so bedeutende, wenigstens kommt sie an Präparaten, die in Alkohol gebärtet waren, nicht in so starkem Maasse zum Ausdruck; hier ist allerdings auch die Membran nur schwach angedeutet, wohl deswegen, weil zu ihrer Darstellung eine vorausgehende Quellung 
nöthig ist. Diese tritt ein bei Fixirung mit Z enker'scher Flüssigkeit - von solchen Präparaten stammen Fig. 7 u. 8 -; der in ihr enthaltene Eisessig verursacht eine Quellung, so dass sich die hier von einer Membran umschlossene Zelle auf Kosten des Intercellularraumes vergrössert. Immerhin kann man auch an Alkoholpräparaten beobachten, dass der Raum deutlich verengert ist. Der Grund hierfur ist wohl ausschliesslich darin zu suchen, dass die nach der Oberfläche zurïckenden Zellen einem vermehrten Druck und Zug ausgesetzt sind, wodurch einmal die Zellen, dann aber auch der zwischen ibnen gelegene Raum in der Richtung von aussen nach innen zusammengepresst werden. R a bl (40) glaubt auf Grund von Sehnitten, die in Alkohol oder M üller'scher Flüssigkeit gehärtet, aber $10-15 \mu$ dick waren, annehmen zu müssen, dass der Intercellularraum von einer Kitt$\mathrm{substanz}$ ausgefüllt sei, da er sich mit Eosin roth färbte. Abgesehen davon, dass Schnitte von solcher Dicke bei so feinen Verhältnissen wenig sichere Bilder geben, ist mir diese Annahme auch an sich nicht recht erklärlich. Die Kittsubstanz müsste doch eine mehr oder weniger feste Konsistenz haben, da sie sich färberisch darstellen lässt, jedenfalls aber gegenüber dem Inhalt der Intercellularräume des Strat. Malp. verändert sei, da dieser keine Farbe anzunehmen pflegt. Auch bleibt rätbselhaft, was weiterhin aus ihr werden sollte, da die Annahme $\mathrm{R}$ a bl's, dass auch zwischen den Zellen der Hornschicht eine Kittsubstanz sich finde, wie unten nachgewiesen wird, unhaltbar ist. Ich verstehe hier überall nach dem Vorschlage F'lemming's (17) unter Kittsubstanz eine den Intercellularraum ausfüllende Masse von festerer Konsistenz. Wodurch sich $\mathrm{Rabl}$ täuschen lassen konnte, wird klar, wenn man erwägt, dass im Strat. gran. an der Zellperipherie eine färberisch nachweisbare Membran entsteht, dass ferner die Intercellularbrï̈cken mit ihren Knötchen persistiren und dabei der ganze $Z$ wischenraum noch eine Verengerung erfährt; an dickeren Schnitten kann dann allerdings der Intercellularraum ausgefüllt erscheinen. Was nun die Intercellularbrucken angeht, so ist, wie eben erwähnt, zunächst festzustellen, dass sie auch innerhalb des Strat. gran. fortbesteben. Während jedoch das Knötchen deutlich bis zum Strat. corneum als Haupttheil sich nachweisen lässt, wird die Faser allmählich unsichtbar. Bei Präparaten, die in Zenker'scher Flüssigkeit fixirt 
waren (Fig. 7), ist sie überhaupt nicht melrr zu erkennen; hier scheint die Brücke nur noch von dem Knötchen gebildet zu sein, die direkt der Membran aufsitzen; ich glaube jedoch, dass dies z. Th. auf Rechnung der Quellung: zu setzen ist, da man an Alkoholpräparaten, wenigstens in den unteren Lagen des Strat. gran., die Faser noch durch die Membran durchtreten sehen kann. Jedoch erscheinen sie in ihrem extracellulären Theil bedeutend verkürrzt, entsprechend der Verengerung des Intercellularraums überhaupt. In der unmittelbar dem Strat. corn. anliegenden Schicht sind nur noch die Knötchen erhalten, die beiderseits einen äusserst kurzen und feinen Stiel zu haben scheinen.

Fassen wir nun die gefundenen Resultate über den $\mathrm{B}$ a u der Z ellen des Strat. gran. zusammen, so können wir folgende Sätze aufstellen:

1) Der Uebergang aus dem Strat. Malp. in das Strat.gran. ist einallmählicher; dabei werden die Zellen in ihrem Dickendurehmesser verkürzt und nchmen im Längsd u r chmesser zu;

2) dasindenZellen autretendeKeratohyalin ist ein Zerfallsproduct der Interfibrillarsubstanz der Z elle;

3) die Protoplasmafasern persistiren und bilden im Zellinner n ein $M$ as chenwerk; das Exoplasmawandelt sich in eine Zell membran um;

4) der Kern geht unablängig vonden Veränderungen des Zellleibs bald früher, bald späterzu Grunde;

5) die Intercellularräume werden verengert; während die Brückenfasern sich verkürzen, bleibt das Knötchen unverändert bestehen; eine Kittsubstanz ist nicht vorbande $n$.

Bevor ich nun zur Besprechung des Baues der Hornschicht ubergehe, muss ich kurz auf die Unters chie de aufmerksam machen, welche zwischen den Epidermiszellen der Vol a ma n us und Planta pedis gegenüber denen der ubrigen $\mathrm{Haut}$ bestehen; es ist das Verdienst $\mathrm{Z}$ a $\mathrm{n} d$ er's (66), diese zuerst be- 
tont zu baben. Alles, was ich oben über den Bau von Strat. Malp. und granul. gesagt habe, bezieht sich auf Untersuchungen von Haut der Vola manus und Planta pedis. Für diese beiden Selichten der Epidermis ist, wie Controlschnitte von den übrigen Hantstellen lehren, der Unterschied jedoch ein geringer, vorwicgend dadurch bedingt, dass an letzteren die Zellen durch das Fehlen der Papillen weniger zahlreich und auch kleiner sind. Daher kommt es, dass die Zellen des Strat. Malp. bei Behandlung nach $\mathrm{Kromayer}$ fast überhaupt nur einen Fibrillenmantel erkennen lassen, in denen der Kern mit nur wenig Interfibrillarsubstanz gelegen ist. Die Intercellularstructur ist die gleiche, wie an der Haut der Handfäche. Da durch die geringe Zellenzahl der Oberflächenzug stärker auf die ein\%elnen Zellen einwirkt, erscheinen diese schon in tieferen Lagen stärker ahgeplattet und imponiren schliesslich gegen das Strat. corn. bin nur noch als schmale Plättchen. An den an diese Schicht anstossenden Zellen war es mir unmöglich, noch einen Intercellularraum, noch weniger eine Structur zn erkennen, sondern hier scheinen die Zellen unmittelbar aneinander zu stossen. Gering entwickelt ist, wie bekannt, das Strat. gran. Während ich in der Brusthaut noch eine einfache continuirliche Lage nachweisen konnte, fanden sich an der Rückenhaut nur einzelne keratohyalinhaltige Zellen, etwas mehr an der Schenkelhaut. Diese Zellen erscheinen, wie sie bereits $\mathrm{Z}$ and er geschildert hat, gegen den Rand zu als äusserst dünne Plättchen, während sie in der Mitte eine kugelige Auftreibung zeigen, in welcher der mehr oder weniger stark zerfallene Kern seine Lage hat. Wo Keratohyalin sich findet, ist es nur in kleinen und wenig zahlreichen Körnern vorbanden; doch scheint wohl jede Zelle Keratohyalin ru bilden. Dass man Zellen trifft, wo dieses feblt, hat darin seinen Grund, dass der Process nicht an allen Stellen zu gleicher Zeit stattfindet, wofür bes. auch Beobachtungen an Vola manus und Planta pedis sprechen, auf die ich später noch zurïckzukommen haben werde. Somit sind die Untersehiede nicht qualitativer Natur, sondernberuhenimwesentliehen n ur a uf der starkeren Abplattung und derdamit verbundenen geringeren Entwickelung der einzelnen Zellstructuren. 
Stratum corneum.

Seitdem Unna $(59,63)$ mit Bestimmtheit nacligewiesen hat, dass sich bei Verdauungsversuchen die ganze Hornschicht vom Strat. gran. bis zur Oberfläche gleich gebaut erweist, ist das als besondere Schicht beschriebene Strat. lucidum von den meisten Autoren nur als der basalste Theil des Strat. corn. aufgefasst worden, als den auch ich es betrachte. Was die Zellen der Hornschicht angeht, so werden sie als stark abgeplattete, trockene und verhornte Schüppchen beschrieben, welche die Eigenschaft baben, in Säuren und Alkalien zu quellen und von Verdauungsflüssigkeit nicht angegriffen $z u$ werden. Letztere Eigenthümlichkeit verdanken sie einer Substan $z$, die als Keratin bezeichnet wird und sich als Unwandlungsprodukt eines Eiweisskörpers darstellt. Gegen die Annahme eines einheitlichen Baues der Hornzellen aller Hautstellen hat Zander (66) den Sať aufgestellt, dass man zwischen zwei Typen zu unterscheiden habe; der Typus $A$ solle sich nur an Vola manus und Planta pedis finden und die Zellen dadurch charakterisirt sein, dass sie bläschenförmige Gcbilde wären mit gut erhaltener Kernhöhle bei fehlendem Kern; der Typus $B$, der an den übrigen Hautstellen vorkommen soll, sei dadurch ausgezeichnet, dass die nach ibm gebaute Hornschicht aus total verhornten Zellen ohne nacbweisbaren Inhalt bestünde, die sich $\mathrm{zu}$ Lamellen aneinanderschliessen whirden; $\operatorname{der}$ Typus $A$ sollte jedoch an den beyeichneten Stellen nicht rein vorkommen, sondern mit Typus $B$ vermischt. Gegen diese Darstellung hat Koelliker (26) den Einwand erhoben, dass auch die Hornschicht des Typus $B$ bei der Maceration in einzelne Zellen auseinanderfalle und diesen Zellen, ebenso wie denen des Typus $A$, die Eigenschaft zukomme, bei Behandlung mit Säuren und Alkalien zu Blasen aufzuquellen. Auch Unna (65̃) schloss sich K o elliker's Entgegnung an, da er nachweisen konnte, dass der Verdaunng gegenäber sich alle Hornzellen gleich verhalten.

Was den Sitz der Hornsubstanz angeht, so scheint in den Kreisen der Dermatologen die Auffassung Unna's sich allgemeiner Anerkennung zu erfreuen, dass das Keratin sich nicht im Zellinnern findet, sondern nur in Form einer Membran, welche die Zelle umschliesst. Demgegenüber finde ich in den anatomischen Lehrbüchern vielfach die Angaben, dass auch im Zellleib selbst Hornsubstanz vorkomme und dass der Grad der Verhornung 
verschieden sei, derart, dass er von der Basis nach der Peripherie fortschreite. Nach Stöhr (56) enthält die Hornzelle an Stellen mit dicker Epidermis ein feines Hornmaschenwerk, zu dem eine Zellmembran hinzukonme; Gegenba ur(19) bezeichnet den ganzen Körper der Zelle als aus Hornstoff bestehend, die Verhornung soll innerhalb des Strat. corn. von der Basis zur Peripherie allmählich zunehmen; von Brunn (7) bezeichnet die Elemente des Strat. lucid. durchweg als verhornt, während die Zellen der darüber befindlichen Lagen nur einen verhornten Mantel besitzen und im Innern von zahlreichen, feinen Hornfibrillen durchzogen sein sollen, die ein feines Maschenwerk darstellten; nur hie und da enthalte die Hornschicht einzelne Lagen vollkommen verhornter, platter Elemente. Diese Aufstellung rührt von Zander (66) her, der das Keratohyalin, bezw. das Eleidin direkt als Keratin ansah; auch Ernst (14) will übrigens mit Hilfe der Gram'schen Methode in den Hornzellen Körner zur Darstellung gebracht haben, die Hornsubstanz sein sollen. Nach Böhm und Davidoff (6) sind dic Zellen namentlich an der Peripherie verhornt, die oberflächlichsten am meisten; nach Rauber (48) enthält jede Zelle ein feines Keratinmaschenwerk und eine starke Keratinhïlle.

In Bezug auf den Bau der Hornzellen hat man zwischen Oberfläche und Zellinnern zu unterscheiden. Nach Ko elliker (26) zeigt die erstere eine feine und dichte Punktirung und gröbere Falten und Leisten neben grösseren Feldern und Kanten; im Innern hat er faserartige, concentrische Streifen beobachtet, ebenso feine, mehr parallelen Fasern ähnliche Bildungen; von dem Keln sollen sich gelegentlich noch Reste nachweisen lassen. Rabl (40) konnte feine Linien sehen, von denen er einen Theil als der Oberfläche, einen andern dem Zellinnern angehörig betrachtet. Un $\mathrm{n}$ a (59) fand isolirte Zellen mit Zacken besetzt, die er für die verkürzten Stacheln der Hornmembran hält; dieselbe Anschauung vertritt Rausch (49), dem es gelang, ein feinkörniges Oberflächenrelief nachzuweisen. Neuerdings hat Merk (35) die Behauptung aufgestellt, dass die Membran der Hornzelle durchlöchert sei und dass durch diese Poren die Verbindungsfäden der einzelnen Zellen hindurchtreten sollen.

Was die Intercellularstruktur angeht, so bleiben nach Unna (59) und Rabl (40) die Zellen der Hornschicht durch die geschrumpften Intercellularbricken mit einander in Verbindung, 
wodurch das feste Gefïge des Strat. corn. bedingt sein soll. Während letzterer noch eine Kittsubstanz annimmt, wird diese von Unna in Abrede gestellt. Koelliker (26) konnte feine Intelcellularräume mit Andentungen von Füden nachweisen, welchc die einzelnen Schüppchen in Verbindung setzen sollen.

Bei der Besprechung des Ba es a er Horns chicht erscheint es mir zweckmässig, insofern von meinem bisherigen Verfahren abzuweichen, als ich die Reihenfolge von innen nach aussen nicht einhalten, sondern in umgekehrter Ordnung vorgehen werde.

Unterwirft man ein Stückchen $\mathrm{Haut}$ von Vola manus oder Planta pedis der Maceration, indem man sich als Macerationsmittel der eingangs erwähnten Flüssigkeiten bedient, so lässt sich schon nach 24 Stunden die Hornschicht als eine breiige Masse abstreichen, die unter dem Mikroskop zahlreiche isolirte Zellen erkennen lässt. Die Zellen erscheinen bald mehr oder weniger abgeplattet, zeigen deutliche Felder an der Seitc, die von dem Druck der Nachbarzellen herrühren und eine undeutlich granulirte Oberfläche, gelegentlich auch feine Strcifungen. Färbt man nun mit concentrirter wässriger Methylviolettlösung; so zeigen sich alle Zellen (Fig. 10) dunkelblauviolett gefärbt mit Ausnahme einer Stelle etwa in der Mitte der Zelle; hier ist eine rundliche Parthie, die wesentlich schwächer tingirt erscheint, aber gegeniuber der Umgebung sich nicht scharf absetzt, sondern allmählich in sie übergeht. Es ist kein Zweifel, dass diese hellere Stelle der leeren Kernhöhle entspricht. Daneben treten nun an der Zelle bald schärfer, bald schwächer gefärbte unregelmässige Felder hervor, die Druckstellen der Nachbarzellen. Als Haupterscheinung fällt aber eine feine Streifung in's Auge; die ganze Zelle wird von Fasern in allen Richtungen durchzogen; durch verschiedene Einstellung des Tubus kann man sich überzeugen, dass jedenfalls der grösste Theil derselben im Zellinnern gelegen ist, während die übrigen der Oberfläche zukommen. Bringt man ein Stückchen Haut von der gleichen Körperstelle in Verdaungsflüssigkeit, so tritt schon nach wenigen Stunden eine Trennung ein; ein Theil löst sich ab, schrumpft zusammen und wird schliesslich aufgelöst, das ist die Kutis mit Strat. Malp. und gran., wäbrend der andere, die Hornschicht, zunächst durch Aufquellen sein Volumen ausserordentlich ver- 
grössert. Dabei haften zuerst die Zellen mit Ausnahmen der oberflichlichen fest aneinander und lassen sich nur durch Zerzupfen mit der Nadel isoliren; bald aber beginnt das ganze Stück, von der Peripherie her fortschreitend, sich in eine breiige Masse unzuwandeln, während im Innern sich noch länger ein festercr Kern erhält. So gewonnene isolirte Zellen zeigen, ohne Deckglas betrachtet, das Bild, wie es in Fig. 11 wiedergegeben ist. Die Zelle ist abgerundet, aufgetrieben und ausserordentlich stark lichtbrechend, so dass sie fast den Eindruck eines Fettropfens macht; die Peripherie wird von einem hellen Saum gebildet. Beim Auflegen des Deckglases schwindet der starke Glanz, um nach Entfernung desselben wiederzukehren; die Form erfährt dabei keine Aenderung. Offenbar handelt es sich hierbei um eine Alteration der Brechungsverhältnisse, weil Zellen, die in der Untersuchungsflüssigkeit tiefer schwimmen, den Glanz nicht reigen, iln aber annehmen, sobald sie an die Oberfläche gelangen. Eine Behandlung solcher durch die Verdauung isolirten Zellen mit Methylviolett zeigt keine wesentliche Aenderung gegeniiber den macerirten, mit Ausuahme ihrer mehr abgerundeten Gestalt.

Hacerirt man nun Haut von anderen Körperstellenes wurde von mir dazu Haut der Hüftgegend verwendet-, so lïsst sich die Hornschicht nicht als breiige Masse abstreichen. Nach ca. 48 Stunden kann man sie in toto als ein zusammenhängendes Häutchen ablösen; um jedoch die Zellen zn isoliren, genügt nicht ein einfaches Abschaben oder ein leichter Druck nit dem Glasstab, sondern man hat noch Mühe, mit der Nadel das Häntchen zn zerzupfen. Die isolirten Zellen sind sehr stark abgeplattet und lassen von einer feineren Struktur kaum etwas erkennen. Bringt man nun Haut von derselben Körperstelle in Verdauungstlüssigkeit, so tritt auch hier eine Trennung ein; während Kutis und Epidermis mit Ausschluss der Hornschicht der Auflösung anheimfällt, löst sich die letztere gleichfalls als ein dünnes Häutchen $a b$, ohne besondere Quellungserscheinungen zu zeigen. Dieses Häutchen zerfällt auch bei sehr langer Einwirkung der Verdaungsflüssigkeit nicht ohne weiteres in einzelne Zellen; ich habe es 14 Tage und noch länger bei $42^{\circ}$ in der Pepsin-Salzsäurelösung gelassen, ohne dass ein Zerfallen eingetreten wäre; eine Lockertung wurde dann allerdings bemerkbar, doch konnten die Zellen nur mit Zuhilfenalıme der Nadel isolirt 
werden. Bei Zellen, die nur einige Tage in der Verdauungsflüssigkeit zugebracht hatten, zeigte sich gegenüher den Zellen von Vola manus und Planta pedis ein auffallender Unterschied, insofern hier die durch die stärkere Lichtbrechung deutlich gecmachte Quellung nur auf einen scharf umschriebenen Theil in der Mitte der Zelle beschränkt blieb (Fig. 12) und diesen als eine deutliche Blase hervortreten liess, während der übrige Zellleib seine abgeplattete, unregelmässig begrenzte Form beibehielt. Färbte man eine Zelle mit Methylviolett, so nahm die ganze Zelle dic Farbe ziemlich gleichmässig an (Fig. 13). Von feinerer Streifung oder Faserung war nichts zu erkennen, höchstens konnte man eine undeutliche Granulirung der Oberfläche beobachten; dagegen zeigten sich auch hier gröbere, dunklere Streifen, die Druckgrenzen der Nachbarzellen. Die centrale Blase batte als auffallendes Merkmal einem scharfen, farbigen Kreis Platz gemacht. Zellen, die aus dem Häutchen nach stärkerer Lockerung des Zellverbandes isolirt waren, wiesen keine centrale Blase mehr auf, dagegen war nun die ganze Zelle, älnnlich wie bei Fig. 11, nur etwas weniger stark aufgequollen.

Zunächst geht aus diesen Beobachtungen hervor, dass die Verbindung der Hornzellen der Vola manus und Planta pedis viel lockerer ist, als die der Zellen der itbrigen Hautstellen, die in Form von Lamellen zusammenhängen. Während ferner erstere unter Einwirkung von Verdauungsflüssigkeit rasch in toto aufquellen, bleibt die Qucllung bei letzteren nur auf eine centrale Stelle, die leere Kernhöhle, beschränkt; der übrige Zellleib zeigt sich anfünglich unverändert, erst bei viel längerer Einwirkung der Verdanungsflussigkeit quillt auch dieser auf. D as Zellinnere der ersteren Zellen wird von einem feinen F a serwerk gebildet, das sich gegen die Kernhöhle undeutlich abgrenzt, daher der verschwommene Umriss; während be i letzteren das Zellinnere faserlos ist und die Zellwände miteinander verklebt sind bis auf die Stelle, wo der Kern lag. Dieser findet sich, wie bereits erwähnt, schon innerhalb des Strat. gran. in einer kugeligen Auftreibung; hier ist also dic nicht verklebte Wandung der Kernböhle scharf von dem übrigen Zelleib abgegrenzt; bei der Färbung zeigt sich diese Grenze daher als ein scharfer Ring. Länger dauernde Einwirkung der verdauenden Reagentien vermag jedoch auch bier die 
verklebten Wände zu lösen; die Zelle quillt dann in gleicher Weise wie die übrigen auf.

Behandelt man Zellen von Vola manus und Planta pedis nach dem von Rausch (49) angegebenen Verfahren, so kann man, wie er angiebt, eine feine Puktirung der Zellobcrfläche beobachten neben einer verschiedenartigen Färbung der einzelnen Zellen, die von blau bis roth alle Farbennuancen zeigen; jedoch vermag ich seine Angabe, dass die rothen Zellen stets glatt seien, nicht zu bestätigen, da ich anch rothe Zellen dentlich punktirt fand. Rausch hat diese Tüpfelung so gedeutet, dass sie die gefürbten, verkürzten Zellstacheln darstellen würde; ich trage Bedenken, mich völlig dieser Auffassung anzuschliessen und zwar aus folgenden Gründen. Die von Ra usch angegebene Methode erzeugt keine eigentliche Färbung, sondern Niederschläge, die bedingt werden durch die Misehung des poly. chromsauren Methylenblau mit dem zur Differenzirung benutzten rothen Blutlaugensalz. Von dieser Thatsache kann man sich leicht überzeugen, wenn man beide Lösungen im Reagensglas mischt oder besser unter dem Deckglas ineinanderfliessen lïsst; es bilden sich dann Niederschläge vom groben Gerinsel bis zu den feinsten Körnern. Dass es sich auch bei der Färbung um solche Niederschläge handelt, geht daraus hervor, dass die Punktirung der Oberfläche ausbleibt, wenn man das Blutlaugensalz weglässt, dann aber auch an dem durchaus unregelmässigen Charakter der Granulirung selbst, die bald grob-, bald ausserordentlich feinkörnig erscheint. Ich habe in Fig. 14 eine solche Zelle wiedergegeben, an der auch gröbere Niederschlïge eingezeichnet sind. Stets babe ich übrigens, was Rausch nicht erwähnt, auch hier die Kernhöhle durch schwächere Tingirung angedeutet gefunden, ein Umstand, der mich veranlasst, für das Innere der Zelle doch eine Färbung anzunehmen. Ueberhaupt möchte ich mit dem Einwand gegen die Raus ch'sche Methode keineswegs eine Reliefbildung in seinem Sinne in Abrede stellen; dass diese thatsïchlich vorhanden ist, dafür vermag ich unwiderlegliche Beweise zu bringen; nur neige ich zu der Annahme, dass nicht die Höhe der 0 berflächenzacken durch die Punktirnng bezeichnet wird, sondern stets die tiefste Stelle um diese herum, in der sich der Niederschlag festsetzen würde. Anf die Deutung der verschiedenen Farben der Zellen werde ich später zurïickkommen. 
Ich gehe nunmehr zu der Besprechung des Aussehens der Hornschicht von Vola manus a u $\mathrm{Sch}$ it ten über. An Präparaten, die in Alkohol gehärtet, 2,5-5,0 $\mu$ dick geschnitten und mit Eisenbämatoxylin gefärbt waren, zeigte sich die Hornschicht vom Strat. gran. bis zur äussersten Peripherie blaugefärbt (Fig. 15). Die Färbung ist im allgemeinen gleichmässig, nur die basalsten Theile, die dem Strat. luc. entsprechen, zeichnen sich durch einen tieferen Farbenton aus. Die Zellen bilden jedoch keine zusammenhängende Masse, sondern sind von einander durch de utliche Intercellularrä ume getrennt, die stets als weisse Linien zwischen den Zellen auftreten und keine Farbe annehmen. Die Form der einzelnen Zellen ist keineswegs so einfach, wie man bisher annahm, und wie die Abbildungen von Koelliker (Fig. 152) oder von Rabl (Fig. 27) wiedergeben, sondern die $\mathrm{Zellen} z$ eige $\mathrm{n}$ eigenthüm liche GabeI ungen und Fortsätze, dic ibrerseits wieder Theilungen unterliegen und in die dann, was die Hauptsache ist, die $\mathrm{Nach}$ barzellen eingreifen, sodass alle Zellen fest ineinandergekeilt erseheinen. Nach der Peripherie, dem Strat. disjunctum $R$ anvier's, zu wird die feste Verkeilung gelockert, wälurend die Zellen ihre abenteuerliche Form (Fig. 16) behalten. Die Zeichnung der Zellgruppen ähnelt der Zeichuung der L a n d es gr e n \% e 1 e i n e r Landkarte, wie Ern s t (14) schon gesehen zu baben scheint. Bei stärkerer Vergrösserung kann man erkennen, dass die Oberfläche der Zelle mit kleinen Fortsätzen bedeckt ist (Fig. 16), die ziemlich dicht nebeneinanderstehen und an ihrem Ende etwas abgerundet sind, ich will sie deswegen als $\mathrm{Z}$ a $\mathrm{h} \mathrm{n}$ chen bezeicbnen. Eine Verbindung dieser Zähnchen durch Fäden lässt sich $\mathfrak{n}$ i e mals weder im basalen noch im peripheren Theil nachweisen; dagegen scheinen sie bald ineinanderzugreifen, bald einander gegenïberzustehen, wie Fig. 17 wicdergibt. Eine Substanz, welche die Intercellularräume ausfïllt, wie sie namentlich von $R$ a bl behauptet wird, läisst sich färbcrisch auf keine Weise zur Darstellung bringen. $D$ as feste Gefügeder Zellender Hornschicht wird demnach nicht durch Verbind ungsäden oder durch eine Kittsubstanzbedingt, sonderndurebdas eigentbümliche Ineinandergreifen der Zellen. Die Abschilferung geschieht in der Weisc, dass durch mechani- 
sche Einwirkung die peripheren Zellen zunächst in ihrer Verkeilung gelockert werden und schliesslich abfallen; die Zähnchen selbst bleiben bis in die äusserste Peripherie unverändert erhalten. Sehr wahrscheinlich kommt dem $\mathrm{Sch}$ we is e nach dieser Richtung hin eine besondere Bedeutung zu, dadurch dass er infolge seines Eindringens in die Intercellularräurne die Auflockerung der Zellen begünstigt; diese scheint nümlich in der Umgebung der Drüsengangsöffnung auf der Oberfäche der Hornschicht bedeutend stärker zu sein als an den übrigen Stellen. Dass übrigens die Zellformen and die Zähnchen keine Kuustprodukte sind, etwa durch eine Schrumpfung in Alkohol bedingt, geht einmal daraus hervor, dass sich die Hornzellen der Einwirkung des Alkohols gegenüber uberhaupt sehr indifferent verhalten, dann aber daraus, dass sich dieselben Verbältnisse auch an Präparaten finden, die in Z enker'scher Flüssigkeit geLärteter Haut entstammen.

Gegenüber der Hornschicht von Vola manus und Planta pedis reigt die der $\mathfrak{i b r i g e n H a u t s t e l l e n ~ e i n ~ a b w e i c h e n - ~}$ d es Verhalten. Hier sind die einzelnen Zellen thatsächlich, wie Z a nder beobachtet hat, zu Lamellen zusammenge$\mathrm{scblossen}$, die in 5-6 Lagen übereinander gesehichtet sind und mit einander an einzelnen Stellen in Verbindung stehen (Fig. 18). In tercellu larrä ume sind hier nieht nachweisbar, ebensowenig Z ähnchen; die Zellen scheinen fest mit einander verklebt. $\mathrm{Da}$ die einzelnen Lamellen durch Zwischenräume von einander getrennt sind, bei der Weiterbehandlung der Schnitte aber das in diese eingedrungene Paraffin gelöst wird, so verlieren solche Lamellen gelegentlich ihren Halt und legen sich um; man erbält so ein Flächenbild, in dem man erkennen kann, dass die Lamellen aus Zellen zusammengesetzt sind (Fig. 19), deren Membranen fest mit einander verklebt erscheinen. Die Lamellen bestehen also aus stark abgeplatteten Zellen, deren Wände aneinanderliegen, dadurch zeigen sie eine doppelte Contourirung; ein Inhalt lässt sich nicht nachweisen.

Wie schon erwähnt, sind die in Alkohol fixirte Zellen von ciner homogenen, gleichmässig gefärbten Masse ausgefüllt. Nur selten kann man eine Zelle beobachten, die in der Mitte eine Durchlöcherung zeigt. Fig. 15 giebt zwei solcher Zellen wieler. Dieses Loch entspricht der leeren Kernböhle. Es 
scheint auffallend, dass Andeutungen einer solchen sicb nur spär. lich finden, während doch nachweisbar jede Zelle ibre Kernhöhle besitzt. Der Grund ist der, dass sie nur dann deutlich wird, wenn sie auf beiden Seiten angeschnitten ist, also direkt ein Loch in dem Zellleib bildet. Bei nur einseitiger Eröffnung wird sie eben durch die Färbung des noch darunter oder darüber gelegenen Zellinhalts verdeckt. Was den $\mathrm{Ke} \mathrm{n} \mathrm{selbst}$ angeht, so konnte ich Reste desselben in Gestalt kleiner Bröckel noch im Ge bi e te des Strat. lucid. beobachten, oft auch noch ganze, allerdings stark geschrumpfte Kerne; in den $o b$ er. flä chli chen Lagen dagegen war die $K$ ernhöhle stets l e er. Ab und zu sielit man auch Zellen, die nicht völlig blau gefärbt sind, sondern ein deutliches Maschenwerk im Innern zeigen (Fig. 20) mit einer mittleren faserlosen Stelle, die der Kernhöhle entspricht. Besser tritt die Faserung a n Hornz e 11 e $\mathrm{n}$ hervor, die in $\mathrm{Z}$ e $\mathrm{nk}$ e $\mathrm{r}$ 'scher Flïssigkeit fixirt waren. Offenbar durch die Einwirkung der M ü lle r'schen Lösung und des Eisessigs ist hier diejenige Substanz, die den Einblick verdeckt, gelöst worden. Man erhält dann Bilder, wie sie Z a n $\mathrm{der}$ gesehen und abgebildet hat. Jedoch zeigen nicht alle Zellen dasselbe Verbalten, sondern ein grosser Theil gleicht denen von in Alkohol fixirten Präparaten, d. h. sie waren mehr abgeplattet, von der oben beschriebenen Oberflächenbildung und mit homogenem Inhalt. Beide Arten hat auch $Z$ a n d e r nebeneinander beobachtet und daraus Veranlassung genommen, einen Theil dieser Zellen als total verhornt zu bezeichnen. Dass dies jedoch nicht zutreffend ist, ergeben ohne weiteres die Verdaungsversuche, von denen gleich die Rede sein wird. Wie R a b l, dessen Argumenten ich mich auf Grund derselben Beobachtung anschliessen kann, schon treffend hervorgehoben hat, handelt es sich bei diesen bläschenförmigen Zellen um Quellungsprodukte, wie auch daraus hervorgeht, dass die Intercellularräume an ihnen völlig fehlen und die Membranen der benachbarten Zellen unmittelbar aneinander stossen; Andeutungen von Zähnchen konnte ich übrigens mehrere Male noch beobachten. Bei Färbung dieser Präparaten mit der Kromayer'schen Methode erkennt man deutlich eine $\mathrm{Me} m \mathrm{bran}$ und $\mathrm{e}$ in $\mathrm{f}$ e ines Maschenwerk im Innern. Ich gebe in Fig. 21 drei derartige Zellen wieder. 
$\mathrm{R}$ a b l hat die Behauptung aufgestellt, dass diese Fasermasse im Innern der Horuzelle nichts anderes wäre als die p e rsistirenden Protoplasmafasern des Strat. M a I p. Diese Annahme glaubt Kro m a y e r (31) mit dem Hinweis entkräften zu können, dass das Fasernetz in letzteren Zellen ein viel feineres sei als das in den Hornzellen, welches er nur für ein Kunstprodukt erklärt. Dem gegenüber trete ich völlig der Ansicht $\mathrm{R}$ a b l's bei und zwar aus folgenden Gründen. Einmal kann dieses Netzwerk continuirlich in allen Zellschichten verfolgt werden, vom Strat. Malp. (Fig. 3), durch das Strat. gran. (Fig. 8) bis in's Strat. corn. (Fig. 21); dass sich das feine Fibrillennetz dabei etwas vermindert, ist obne wesentliche Bedeutung; die Veränderung besteht, wie wir sehen werden, vor allem darin, dass es der Verdauungsflüssigkeit gegenüber etwas widerstandsfähiger geworden ist. Zweitens lässt es sich durch alle Schichten mit Hilfe der $\mathrm{Kr}$ om a y e r'schen Methode nachweisen; wenn es also in einer Schicht Kunstprodukt ist, so müsste man annehmen, dass das gleiche auch in anderen Lagen der Fall ist; mir ist jedoch nicht bekannt, dass die so dargestellten Fasern von $\mathrm{Kr}$ o ma yer selbst oder von anderen Autoren für Kunstprodukte gehalten werden. Endlich müsste doch noch ein Zerfallsprodukt der Protoplasmafasern nachweisbar sein, wenn diese auf dem Wege zur Horuschicht zu Grunde gehen würden. Da aber feststeht, dass das Keratohyalin als solches nicht anzusehen ist, baben wir mit $R$ abl das $M$ a s chenwerk d c r Hornzellen als die persistirende Fibrillarmasseder Zellen des Strat. Malp. und gran. alfzufassen.

Ebenso wie der im Zellinnern gelegene Theil der Fibrillarsubstanz sich in den Zellen des Strat. corneum erhalten hat, trifft dies für den peripheren, das Exoplas ma, zu. Wir haben gesehen, dass sich dessen Fibrillen innerhalb des Strat. gran. zu einer deut i chen Membran verdichtet haben, und diese Membran finden wir wieder im Strat. corneum nur mit dem Unterschiede, dass sie sich hier als völlig $\nabla$ e rhornt erweist. Ihre Zusammensetzung aus einzelnen Fasern lässt sich noch an dem Oberflächenbau der Hornzelle erkennen, auf deren streifigen Charakter ich oben aufmerksam gemacht habe. Neben

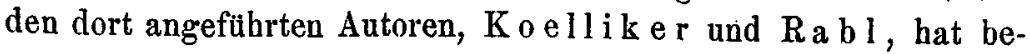


sonders auch $\mathrm{R}$ a n vie $\mathbf{r}$ (47) Beobachtungen in der gleichen Richtung gemacht; er sagt von den Zellen der basalen Lagen des Strat. lucid.: Elles possèdent une enveloppe dans laquelle se tronvent des fibrilles épidermiques enroulées comme les fils d'un cocon.

Es frägt sich nun noch, woher die eigenthümliche $Z \ddot{a} b n$ c b e n stammen, welche der Oberfläche der Hornzelle aufsitzen. Die Zellen des Strat. granul. sind, wie oben beschrieben, noch mit einander durch Intercellularbrücken verbunden, die aber in der Hauptsache hier nur noch aus den medialen Knötchen bestehen, während die Faser selbst bedeutend verkürzt ist. Am Uebergange des Strat. gran. in das Strat. corn. sind jedoch nur noch $\mathrm{Kn} \ddot{\mathrm{t}} \mathrm{ch}$ en nachweisbar. Diese bilden sich zu den Zähnchen der Hornzelle um, wobei sie wahrscheinli ch in der Mitte durch reissen, ein Vorgang, der mit einer geringen seitlichen Verschiebung der getrennten Stücke gegen einander verbunden sein kann. Dadurch wird die Verbindung der beiden Zellen gelöst, sodass innerhalb der Hornschicht keine Brücken mehr vorhanden sind. Dass es zu einer Trennung des Knötchens in zwei gleiche Theile kommt, geht daraus herror, weil man stets sieht, dass an die Stelle, wo ein Knötchen lag, bei der Umwandlung in die Hornzelle ein Zühnchen getreten ist. Es kann sich jedoch nicht das ganze Knötchen umgebildet haben, weil ja sonst der gegenüber liegenden Zelle nach ibrem Uebertritt ins Strat. corr. ein Zähnchen fehlen müsste; ein solches Verhalten ist jedoch nicht zu konstatiren. Jede Hornzelle zeigt vielmehr ihren Rand mit Zähnchen besetzt, die genau soweit von einander entfernt sind wie die Knötchen des Strat. granul. Die direkte Beobachtung, dass eine Hornzelle ein deutliches Zähnchen hatte, während die anstossenden Zelle des Strat. gran. ein derselben Brücke angehöriges, verkleinertes Knötchen aufwies, ist mir allerdings nicht gelungen; es liegt dies daran, dass die Knötchen ihre Farbe schon abgegeben haben, bevor die Zähnchen scharf differenzirt sind. Darum ist der Beweis für die Theilung nur indirekt $\mathbf{z u}$ erbringen. Sobald also die seit ihrer Entstehung mit einander durch Brücken verbundenen Zellen diesen Zusammenbang lösen, scheint auch das Knötchen sich za theilen; damit gewinnt die Annahme, dass dieses Gebilde nur genetisch $\mathrm{zu}$ betrachten ist und nur die Zellgrenze markirt, an Bedleutung.

Die Frage nach clem Sitze der Hornsubstanz 
kann $\mathrm{nur} d \mathrm{ur}$ e h Verda u u g s versuche gelöst werden. Bringt man Hantstückchen von Vola manus oder Planta pedis in die Verdaungrsflüssigkeit, so vollziehen sich zunächst die bereits oben geschilderten Vorgänge, die Auflösung der Kutis und die Quellung der Hornschicht. Ich habe nun ein solches gequollenes Hornstückchen, noch ehe der Zellverband zu sehr gelockert war, in fliessendem Wasser gebörig ausgewaschen, in Alkohol gehärtet, in Paraffin eingebettet and 2,5 $\mu$ dick geschnitten. Dabei zeigte nun die ganze Hornschicht rom Strat. gran. bis zur Peripherie das gleiche Verhalten. Sämmtliche Zellen sind bläschenförmig aufgequollen (Fig. 22), von einer deutlichen Membran umgrenzt und mit einem reichen Maschenwerk im Zellinnern erfüllt, von dem nur eine mittlere ovale Stelle, die Kernhöhle, frei bleibt. Intercellularräume sind nicht vorhanden; die Membranen der benachbarten Zellen liegen direkt auf einander; hie und da sind Andeutungen von Zähnchen zu erkennen. Das Bild ist also dasselbe wie bei den mit Z enker'scher Flüssigkeit fixirien Präparaten, nur mit dem Unterschiede, dass jetzt alle Zellen dea gleichen $\mathrm{Bau}$ zeigen. Damit ist bewiesen, dass $\mathrm{Z}$ a $\mathrm{nder}$ im Unrecht ist anzunehmen, dass innerhalb der Hornschicht der Vola manus und Planta pedis sich total verhornte Zellen finden. Die an der äussersten Schnittperipherie gelegenen Zellen zeigen einen Theil ihres faserigen Inhalts gelöst und nur noch von einer Membran umgeben (Fig. 23).

Unterwirft man nun einen derartigen $\mathrm{Sch}$ itt $\mathrm{noch}$ mals der Verdauung, so löst sich das ganze Fasernetz im Innern jeder Zelle; es bleibt nichts zurück als die M embran, ảie mit der der Nachbarzelle zu einer einzigen Lamelle verklebt erscheint (Fig. 24). Die Angaben Un n a 's (59), dass noch eine fädige Verbindung zwischen diesen beiden Membranen vorhanden sei, kanu ich ebensowenig wie Behn (2) und Rabl (40) bestätigen. Niemals habe ich etwas gesehen, das auch nur im entferntesten im Unna'schen Sinne hätte gedeutet werden können; die Zellgrenzen waren stets durch eine einfache Lamelle markirt.

Interessant ist der Verdauungsversuch mit Haut von der Hüftgegend. Das abgelöste Häutchen, ausgewaschen, in Alkohol fixirt und geschnitten, erscheint aus Lamellen aufgebaut, die abgesehen von einer etwas grösseren Lockerung der lamellösen 
Lagen untereinander genau dem Bilde von nicht verdauter Haut entsprechen (Fig. 18). Auch hier ist die Doppelkontourirung deutlich. Bringt man aber einen derartigen Schnitt nochmals in die Verdauungsflüssigkeit, so lösen sich die Lamellen zu einem Netzwerk auf (Fig. 25); die doppelte Kontourirung ist versehwunden; anstatt der dicken Bänder zeigen sich feine Linien kurz das Bild ist das gleiche wie das von der Haut der Planta pedis gewonnene. Daraus kann man schliessen, dass d en Zell en der übrigen Hornschicbt das feine Faserwerk $f e b l t ;$ jedoch sind die aneinander liegenden Zellwände nicht miteinander verwachsen, sondern nur verklebt und lassen sich bei direkter Einwirkung von geeigneten Reagentien abheben. Der Verdauungsversuch stützt also das schon durch die Behandlung isolirter Zellen gewonnene Resultat.

Damit komme ich zur Bestätigung des schon längst von Unna $(59,63)$ aufgestellten Satzes, dass die Hornsubstanzder Hornzellen nur auf die Membran beschränt ist, dass ferner die basalen Zellen der Hornschicht - das Strat. lucid. inbegriffen - genau in gleichem Grade verhornt sind wiedie am weitesten peripher gelegenen, und drittens dasseine regionäre Differenz in dieser Beziebung fär die verschiedenen $\mathrm{Hat}$ at tellen nicht besteht. Das Keratohyalin kann also, wie $\mathrm{Z}$ ander annahm, ebensowenig Hornsubstanz sein, wie die von Ernst (14) beschriebenen Granula im Innern der Zelle. Wenn man eben nur die Sub. stanz als Keratin bezeichnet, welche der Verdauung widersteht, so kann anch das in der Zelle gelegene Maschenwerk nicht als verhornt bezeichnet werden, da es bei angeschnittener Zelle sich löst. Der Umstand jedoch, dass die Fibrillen ausserordentlich säurebeständig zu sein scheinen, insofern sie entgegen der die Maschen ausfüllenden Masse bei Verdauung in toto nicht zerstört werden, machte es wahrscheinlich, dass doch die Fasern in ihrer Zusammensetzung irgend eine Umwandlung erfahren haben, jedenfalls nicht mehr aus dem gleichen Eiweisskörper bestehen wie innerbalb des Strat. Malp.

Die Unterschiede zwischen den Hornzellen der Vola manus und Planta pedis und den nach dem 
$\mathrm{Z}$ ander's che n Ty p u $B$ gebauten Hautstellen sind lediglich dureh mechanische Momente bedingt. Wie schon früher hervorgehoben, ist der Druck und Zug, den die einzelnen Zellen bei ihrem Vorrücken nach der Peripherie erleiden, um so stärker, je geringer die Zellenzahl ist. Die Zelle wird also in letzterem Falle früher abgeplattet und in die Länge gezogen; damit werden auch die Intercellularräume bis zum völligen Verschwinden verengert, sodass die Zellen fest aneinander liegen. Bei der Kleinheit der Zellen im Strat. Malp. ist eigentlich nur die periphere Fibrillenmasse stärker entwickelt; indem sich diese zur Hornsubstanz umwandelt, werden infolge des gesteigerten Zuges und Druckes die Zellwände aufeinander gepresst. Dadurch geht das ohnehin nur in Spuren vorhandene Maschenwerk im Zellinnern zu Grunde; die Wände verwachsen jedoch nicht miteinander, da wohl die Zellen keine aktive Lebensthätigkeit mehr entfalten können, sondern es kommt nur zu einer festen Verklebung. Wie die Wände ein und derselben Zelle sich aneinander legen und so ein anscheinend total verhorntes Plättchen gebildet wird, vollzieht sich der gleiche Vorgang zwischen den Nachbarzellen; auch hier kommt es nur za einer festeren Verklebung der einander zugekehrten Membranseiten, die durch geeignete Mittel jedoch gelöst werden kann.

Neuerdings hat Merk (35) die Theorie aufgestellt, dass dem Plasma der Hornzellen eine Lebensthätigkeit zukomme, die sich darin äussern soll, dass die Zellen durch angebliche ihre Membran durchsetzende Por en im Stande seien, uberflussige Flüssigkeitsmengen aus dem tiefer gelegenen Gewebe in sich aufzunehmen und durch Verdunstung an die Oberfäche abzugeben; es komme ihnen so eine bedeutende regulatorische Thätigkeit zu. Merk kam zu dieser Annahme, weil er beobachtet hatte, dass bei Injektionen in die Fingerbeere die basalen Hornzellen gequollen waren. Ganz abgesehen davon, dass eine des Kerns entbehrende Zelle noch aktive Lebenserscheinungen zeigen soll, ist die anatomische Grundlage der Theorie unrichtig; denn Poren, welche die Zellmembran durchsetzen, existiren nicht; wären solche vorhanden, so müssten sie sich doch bei ganz oder theilweise verdauten oder mit Alkalien behandelten, aufgequollenen Zellen auf dem Durchschnitte als Unterbrechungen der Membran zeigen; derartige Lücken kann ich aber nirgends finden, noch sind 
sie je von anderen Autoren beschrieben oder abgebildet worden. Ferner aber hat $\mathrm{Merk}$ den in diesem Falle wichtigen Unterschied zwischen den Hornzellen der Vola manus und der übrigen Haut nicht beachtet. An den letzteren ist es absolut unmöglich, Flüssigkeit in das Innere der das Strat. corn. bildenden Hornlamellen hineinzupumpen. Wie schwer sich hier die aneinander liegenden Zellwände lösen, beweisen meine oben angeführten Versuche. Die ganze von $\mathrm{Merk}$ behauptete regulatorische Thätigkeit würde sich also bestenfalls auf die Hornschicht der Vola manus und Planta pedis beschränken können.

Es bleibt nun noch die Erörterung über d i eje ni g e Substan\%, welche das Maschenwerk der Hornz e I l e n a u f ïllt. Bekanntlich war es R a n vier (44), der zuerst innerhalb des Strat. lucid. eine eigenthümliche, fettartige und tropfenbildende Masse beschrieb, die sich besonders mit Pikrokarmin lebhaft färbte, und von ihm als Eleidin bezeichnet wurde. Dieses Eleidin füllte die basale Hornzelle und floss beim Anschneiden aus. In den mehr peripher gelegenen Theilen der Hornschicht war diese Masse nicht mehr nachweisbar; weder zeigten sich hier die charakteristischen Tropfen noch die spezifische Pikrokarminfärbung. Das Eleidin blieb also auf die basale Lage beschränkt; ihm soll das Strat. Iucid. seinen eigenthümlichen matten Glanz verdanken, den $\mathrm{O}$ e h I (37) zu dieser Namengebung veranlasste. An den iibrigen Hautstellen - die eben gemachten Angaben beziehen sich nur auf Vola manus und Planta pedis - war weder im Strat. lucid. noch in den böheren Lagen deutliches Eleidin nachweisbar. Nach den Untersuchungen von Dreysel und Oppler (10) soll es sich nur ab und $z n$ in Spuren in der basalsten Zellreihe der Hornschicht vorfinden. Ueber die Herkunft des Eleidins gehen die Ansichten auseinander. Von Ranvier, Rabl u. a. wird es als das Umwandlungsprodukt des Keratohyalins betrachtet, während die beiden oben genannten Autoren und mit ibnen Buzzi, wenigstens in seiner ersten Arbeit (8), Eleidin und Keratohyalin als Substanzen ansehen, die wenig mit einander zu thun haben.

Wenn man die Haut in Alkohol oder Formol gehärtet hat, so erscheint, wie bereits erwähnt und in Fig. 15 wiedergegeben, der Inhalt der Hornzellen als eine homogene Masse, in der im Allgemeinen kein feinerer Ban, insbes. kein 
Netzwerk zu erkennen ist. Die basalen Theile, d. h. die 3 bis 4 untersten Zelllagen, unterscheiden sich von den übrigen nur durch die intensivere Färbung vor allem bei Verwendung von Eisenhämatoxylin. Bei Hautstïcken, die in $\mathrm{Z}$ en k e r'scher Flüssigkeit fixirt (Fig. 21), oder bei solchen, die in toto der Verdauung unterworfen waren (Fig. 22), tritt nun bei Anwendung der gleichen Färbungsmethoden ein deutliches Maschenwerk hervor, während der zwischen den Fasern gelegene Theil völlig ungefärbt bleibt. Daraus folgt, dass die gleichartige Färbung im ersteren Falle bedingt ist durch das Vorhandensein einer Substanz, die das Maschenwerk völlig ausfüllt, durch entsprechende Behandlung jedoch in Lösung geht und sich dadurch dem färberischen Nachweis entzieht; damit tritt das unveränderte Zellgerïst hervor. Nun haben bereits Dreysel und Oppler nachgewiesen, dass das Eleidin in allen stärkeren Säuren lösbar ist, aber auch in Mülle r'scher Flüssigkeit; bei der Z e n k e r'schen wirken zur Lösung mit der letzteren der Eisessig zusammen, bei der Verdauungsflüssigkeit die Salzsäure. Damit ist bewiesen, dass die das Fasernetz der Hornzellen ausfüllende Masse das Eleidin ist. Es hat Grosse (20) die Behauptung aufgestellt, dass das Eleidin in Alkohol fest werde und dann auf dem Schnitte nicht mehr austrete; dieser Anffassung traten jedoch Dreysel und Oppler entgegen, da sie nachweisen konnten, dass attch bei Alkoholfixirung des Eleidin seinen flüssigen Charakter behält. Thatsächlich füllt es doch die Zellen des Strat. lucid. aus; wenn es also in derselben Lage einmal fest, das andere Mal mehr fliissig erscheint, so liegt der Grund in der verschiedenen weiteren Behandlung der Präparate. Der Ausdruck Eleidin ist reservirt für die in den basalen Theilen der Hornschicht gelegene Masse, deren Haupteigenschaft ihre flüssige Beschaffenheit ist. Da nun die Zellen der ganzen Hornschicht mit einer homogenen Substanz sich gefüllt erweisen, die sich im basalen Theile, wo sie das Eleidin darstellt, nur durch eine stärkere Aufnahmefähigkeit für Farbstoffe auszeichnet, Säuren gegenüber aber sich in der ganzen Schicht gleich verhält, so haben wir es in den übrigen Zelllagen mit einer Masse zu thun, die ein Deri$\checkmark$ at des Eleidins ist; diese Substanz ist besonders dadurch charakterisirt, dass sie eine mehr feste Consistenz hat und infolge dessen aus der angeschnittenen Zelle nicht auszu- 
fliessen vermag. Der Kürze wegen bezeichne ich sie als $\mathrm{P}$ ar e I e i d in.

Um die Frage nach der Herkunftes Eleidins zu lösen, bedarf es nur der einfachen Beobachtung der Zellen an der Uebergangszone aus dem Strat. gran. in das Strat. corn. Neuerdings hat Ranvier (47) das Stat. lucid. in zwei Schichten eingetheilt, eine basale, unmittelbar an das Strat. gran. grenzende, die er als Strat. intermedium bezeichnet, und eine periphere, das eigentliche Strat. lucid. Die erstere Lage soll sich von letzterer dadurch unterscheiden, dass sie bei Fixirung in Osmiumsäure nach Pikrokarminfärbung als ein lebhaft roth gefärbtes Band erscheint, während das letztere ungefärbt bleibt; dieses Band soll aus 2-3 Zelllagen bestehen und seine periphere Abgrenzung eine gleichmässige sein, seine basale dagegen ausgezackt (festoné). An Präparaten, die in Alkohol fixirt und mit Eisenhämatoxylin gefärbt sind, scheint der Uebergang der Zellen des Strat. gran. in die des Strat. lucid. dadurch auffallend charakterisirt, dass die Keratohyalinschollen, mit denen die Zellen der ersteren Lage vollgepfropft sind, plötzlich verschwindeu und einer diffusen Blaufärbung der ganzen Zelle Platz machen. Die Umwandlung trifft jedoch nicht die Zellen der peripheren Lage des Strat. gran. alle gleichmässig, sondern sie unterliegen vereinzelt dem Process; man findet also zwischen Zellen mit noch deutlichen Keratohyalinschollen solche, in denen an Stelle der letzteren schon jene homogene Masse getreten ist. Figur 26 giebt ein derartiges Bild wieder. So entsteht das eigenthümliche „festonnirte" Aussehen, wie es Ranvier geschildert hat. Es unterliegt keinem Zweifel, dass die homogene Substanz, die nun im Strat. lucid. die Zelle diffus erfüllt, also das Eleidin, nichts anderes ist, als die ineinander geflossenen Keratohyalingranula. Der sichere Beweis wird dadurch erbracht, dass sich thatsächliche Uebergänge von einer in die andere Form finden lassen. Ich gebe in Fig. 27 eine solche Zelle wieder, die nach der Kromayer'schen Methode gefärbt ist; während die eine Hälfte noch deutlich Schollen aufweist, ist die andere bereits diffus erfüllt; nach dem Grade der Färbung erkennt man, dass die dichteste Stelle am Rande liegt und nach der anderen Seite zu, also gegen den noch nicht zerflossenen Theil, abnimmt. In Fig. 26 ist die links gelegene Zelle noch mit getrennten Granula 
vollgepfropft, während die rechte eben zerflossen ist; die ursprünglichen Schollen lassen sich noch an der dunkleren Färbung erkennen, die $\mathrm{Z}$ wischenräume zwischen den Granula, die erst durch das Zerfliessen ausgefüllt werden, an der helleren Tinction. Fig. 28 zeigt einen Schnitt, der mit Hämalaun und van Gieson'scher Mischung gefärbt ist; die Zelle am weitesten links lässt noch einzelne distincte Granula erkennen, die mittlere ist im Zerfliessen begriffen, befindet sich also etwa in demselben Stadium, wie die rechte in Fig. 26, während die Zelle rechts schon eine diffuse Infiltration aufweist. Interessant ist auch die Beobachtung Buzzis (9), der ursprünglich (8) den Standpunkt vertrat, dass beide Körper nichts miteinander zu thun hätten; er fand an Warzen, dass Eleidin innerhalb der Zellen des Strat. gran. neben Keratohyalin aufgetreten war, und neigt daraufhin zu der Annahme, dass trot $z$ topographischer, morphologischer und chemischer Verschiedenheit das Eleidin vom Keratohyalin herstammt. Ranvier (47) driickt den Zusammenhang beider Substanzen durch folgenden Sat\% aus: L'éléidine granuleuse s'est transformée en éléidine diffuse. Durch das Zerfliessen erklärt sich auch der anscheinend ganz unvermittelte Uebergang vom Strat. gran. in das Strat. corn. in der einfachsten Weise.

Was den Zusammenfluss bedingt, nuss einstweilen dahingestellt bleiben; es scheint mil jedoch im höchsten Grade wahrscheinlich, dass Lösungsprodukte des Kernes es sind, die, in das Protoplasma der Zelle übertretend, das Keratohyalin verflüssigen, weil die Zone, in der der Hauptzerfall des Kerns sich vollzieht, mit jener Uebergangszone zusammenfällt.

Durch die Umwandlung des körnigen Keratohyalins in das flüssige Eleidin wird die Hornzelle von einer homogenen Substanz erfüllt, in der man, wenigstens bei Färbnng mit Eisenhämatoxylin kein Maschenwerk mehr erkennen kann, während es nach den Angaben von Unna und Rabl bei Behandlung nach der Kromayer'schen Methode sichtbar sein soll; ich muss gestehen, dass es mir nicht gelungen ist, etwas derartiges festzustellen; Zellen, wie sie Fig. 20 wiedergiebt, waren nur sehr spärlich vorbanden und lagen in mehr peripheren Schichten. Der Grund, warum das Faserwerk nicht hervortritt, ist darin zu suchen, dass das durch die Behandlung festgewordene Eleidin sich dem Farbstoff gegenüber ebenso verhält, wie das Netzwerk und die Mem- 
bran; möglicherweise bestehen geringe Differenzen in Bezug auf die Stärke der Färbung, ohne dass sie sich aber bes. bemerkbar machten. Die gleiche Färbbarkeit aller Zelltheile wird an der Intercellularstructur sehr deutlich. So lange das Keratohyalin noch vorhanden ist, kann man die Brückenknötehen als Punkte wahrnehmen, die von den peripheren Keratohyalingranula scharf - durch die nicht gefärbte Membran - getrennt sind; mit dem Moment des Zerfliessens hört jedoch die Trenuung auf und die Knötchen erschienen nun direct als die Zähnchen der Hornzelle in gleiclımässiger Färbung mit deren Inhalt (Fig. 27).

Diejenigen Autoren, die Keratohyalin und Eleidin als nicht zusammengehörig betrachten, schliessen dies aus mehr oder wcniger grossen Differenzen beider Substanzen chemis chen Reagentien gegrenüber. Da ich nach dieser Seite hin die beiden Körper nicht vollständig untersucht habe, kann ich auf eine Kritik der betreffenden Angaben nicht näher eingehen. Jedenfalls verhalten sich aber beide Substanzen in einer ganzen Reihe von Punkten gleich nnd, soweit ich dies beobachtet habe, will ich es anfïhren. Es ist stets behauptet worden, dass das Keratohyalin sich sehr stark mit Hämatoxylin färben lasse, das Eleidin dagegen nicht oder nur einen schwachen Ton annehme. Ich habe diesen Versuch nachgeprüft und mich zu der Färbung des Hämalauns bedient, zunächst ohne mit Eosin oder mit einem anderen Farbstoff nachzufärben. Das Keratohyalin nimmt allerdings diese Farbe sehr stark an, aber auch das Eleidin färbt sich, wenn auch schwächer; kein Unterschied besteht dagegen bei Anwendung des Eisenhämatoxylins, wie ein Blick auf die diesbezüglichen Fig. 15 und 26 ohne weiteres zeigt. Auch bei der Anwendung der Kromayer'schen Methode färben sich beide Stoffe gleich. Färbt man mit Hämalaun und PikrinsäureFuchsinmischung nach van Gies on (Fig. 28) so lange, bis das Strat. corn. intensir gelb erscheint, so ist zunächst der Unterschied zwischen Strat. gran. und Hornschicht auffallend. Man kann jedoch erkennen, dass auch innerhalb des Strat. gran. die zwischen den Keratobyalinschollen gelegenen Stellen gelb gefärbt sind, ebenso die Intercellularbrïcken und die Membran; der fibrilläre Zelltheil zeigt also eine grosse Affinität zm Pikrinsäure, das Keratohyalin zum Hämalaun; ist es zerflossen, so wird die Vorliebe für den letzteren Farbstoff eine geringere; damit 
bekommt die Pikrinsäure das Uebergewicht und färbt nun auch das Eleidin. Dies geht daraus hervor, dass man bei zerfliessendem Zellinhalt noch Schollenreste sehen kann, die einen blauen Grundton haben, aber bereits gelb überfürbt erscheinen. Auf dieselbe Weise lassen sich noch andere färberische Unterschiede erklären, besonders auch die bei Anwendung des Eosins. Weitere Beweise für die nahe Beziehung beider Körper ist ihre Löslichkeit in der Z enker'schen Flüssigkeit und der Salzsäure, wie bereits oben angegeben wurde. R a nvier (49) ist es sogar gelungen, durch Behandlung von Hautstückehen mit Chlornatrium die Keratolyalingranula schon innerhalb des Strat. gran. zum Zerfliessen zu bringen. Das alles beweist doch, dass auch nach der chemischen Seite hin, der Unterschied beider. Substanzen nur ein minimaler sein kann. Dass übrigens dieser auch dann bestehen kann, wenn ein Körper ans dem anderen hervorgeht, ist selbstrerständlich. Als Momente, die eine Veränderung beider Substanzen hervorbringen können, verweise ich auf die geringere Concentration des Eleidins gegenüber der compacten Masse des Keratobyalins, die bes. bei der Affinität zu Farbstoffen eine Rolle spielen dürfte, dann aber auch auf den Umstand, dass der Uebergang in den fluissigen Aggregatszustand eine Mischung mit den ubrigen Zellbestandtheilen bedingt, bes. mit dem Zellsaft und den Lösungsprodukten des Kerns, deren Einwirkung auf die chemische Zusammensetzung: und Reaktion des Zellinhalts sich unserer Berechnung entzieht.

Das Eleidin geht, wie oben auseinandergesetzt, in den höheren Lagen wieder in einen festeren Körper über, den ich als Pare le id in bezeichnet habe. Diese Substanz ist es nun, die noch bestimmte Veränderungen einzugeheu scheint, die wir wohl als das a natomische Substrat der von Unna (58) und Anderen beschriebenen $f a ̈ r b e r$ is chen $D$ ifferenzen der verschiedenen L a en der Hornschicht, besonders gegenüber der Osmiumsäure und dem Pikrokarmin, ansehen müssen, da die Verdaunngsversuche lebren, dass die übrigen Zellbestandtheile, die Membran und das Maschenwerk, innerhalb der ganzen Hornschicht gleich gebaut sind und sich nicht verändern. Ich glanbe, dass auch auf die Beschaffenheit des Pareleidins alle die Befunde zazïckzuführen sind, welche auf die Anwesenheit von Fett oder ähnlichen Substanzen in der Haut deuteu. Ohnie mich auf diese 
Frage hier näher einzulassen, möchte ich die Aufmerksamkeit nur anf einen Punkt richten, der mir für ihre Beurtheilung ausserordentlich wichtig scheint und auf den ich in der Literatur keinen Hinweis finden konnte. Das ist die $\mathrm{Fr}^{\mathrm{a}} \mathrm{ge} \mathrm{nach} \mathrm{der}$ Einwirkung des Schweisses auf die Hornzellen. Bekanntlich verhalten sich die Zelllagen der Hornschicht nicht nur von innen nach aussen färberisch verschieden, sondern, worauf Rabl $(40,42)$ aufmerksam gemacht hat, es bestehen auch Abweiclungen zwischen dem suprapapillären und dem interpapillären Theil des Strat. corn., derart dass sich z. B. ersterer mit Pikrokarmin dunkelroth färbt, letzterer dagegen blassroth, bei Bebandlung mit Hämatoxylin und Methyleosin, jener blan, dieser roth. Nun hat $\mathrm{R}$ a u s ch (49) gleichfalls, wie bereits elwähnt, die Hornzellen bei Behandlung mit polychromsaurem Methylenblau verschieden gefärbt gefunden und zwar blaue und rothe Zellen und zwischen ihnen alle Uebergänge. Er ist wie auch Rabl der Ansicht, dass diese Erscheinung auf den grösseren oder geringeren Fettgehalt zurückzuführen sei. Ich möchte dafür Pareleidin setzen, aber weniger die Menge dieser Substanz dafür verantwortlich machen, als vielmehr eine bestimmte Reaktion des Zellinhalts. Man kann sich nämlich leicht überzeugen, wenn man polychromsaures Methylenblau im Reagensgglas einmal mit Essigsäure, dann nit Kalilauge behandelt, dass im ersteren Falle eine deutliche Blanfärbung eintritt, im letzteren eine rothviolette, besonders auffallend nach Zusatz von etwas Alkohol. Der Versuch gelingt auch bei der Färbung von Zellen. Ich wählte zu diescm Zwecke Epithel der Mundhöhle; auf einen Theil desselbcn liess ich längere Zeit Essigsäure einwirken, auf einen andern ebensolange Kalilauge; die mit ersterer Flüssigkeit belandelten Zellen zeigten eine mebr bläuliche Färbung, die letzteren eine mehr röthliche. Man kann also sagen, Zellen. mit saurer Reaktion neigen bei Behandlung mit polychromsaurem Methylenblau zu einer blauen Tingirung, mit alkalischer Reaktion zu einer rotben. Säuren und Alkalien vermögen aber nicbt nur die Reaktion des Zellinhalts zu ändern, sondern auch diesen selbst zu lösen, wie für das Eleidin und Pareleidin bewiesen ist. Daneben hat aber noch Ranier (47) in dem Chlornatrium ein Mittel gefunden, das besonders das Eleidin angreift, indem es in ihm Vacuolen bildet und Lösung verursacht. E in e s o l c h e Fli ssig- 
keit, die theils durch ihren Salzgehalt, theils durch die in ihr enthaltenen Säuren oder Alkalienzersetzend a u den Inhalt der Hornzellen einwirken kann, ist der Schweiss, der bald sauer, bald besonders bei längerem Stehen alkalisch reagirt. Der Bau der Ausfuhrgänge der Schweissdrüsen begünstigt eine unmittelbare Umspülung der Hornzellen mit diesem Excret auf doppeltem Wege. Einmal besitzen diese Gänge, sobald sie in das Strat. corn. eintreten, nach den Untersuchungen von $\mathrm{K}$ o e l l i k e r (26) keine eigene Wand; ein Weg wird nur durch Auseinanderweichen der Zellen gebildet. Durch die Intercellularräume, die wie Kapillaren wirken, kann von diesen Gängen aus der Schweiss aufgesogen werden und die Zellen umsplilen. Dann aber liegt die Ausmündungsstelle auf der Oberfläche in einer trichterförmigen Einsenkung; hier könnte also der Schweiss stagniren und von hier aus in die tieferen Schichten eindringen. Da nun die Ausführgänge stets im intrapapillären Theil der Epidermis gelegen sind, so würde dieser Theil mehr mit der Flüssigkeit imprägnirt sein als der entferntere suprapapilläre und darin könnte die Ursache für die verschiedene Färbbarkeit dieser Partien liegen. Das alles sind Erwägungen, die noch eingebender Untersuchung hedürfen. Jedenfalls möchte ich neben der austrocknenden Wirkung der Luft dem Schweiss den Hauptantheil an den Veränderungen zusprechen, denen der Inhalt der Hornzelle unterliegt.

Hinsichtlich des Baues der Hornschicht und ibrer Zellen lassen sich also folgende Sätze aufstellen:

1. Die Zellen der Hornschicht sind mehr oder weniger stark abgeplattete, kernlose Gebilde, an denen sich eine Membran, ein Netzwerk von feinen Fasern und eine dieses erfüllende homogene Substanz neben einer leeren Kernhöhle nachweisen lässt.

2. Die Verhornung hat ihren ausschliesslichen Sitz in der Membran; das Fasernetz besteht aus verändertem Protoplasma, ist jedoch verdaulieh.

3. Die das Maschenwerk erfüllende Substanz erleidet auf dem Wege bis zur Peripherie gewisse Umwandlungen; sie bildet im hasalen Theil das Eleidin, in den dar über gelegenen Lagen das Pareleidin.

4. Der Zusammenhang der Zellen wird durch eigen- 
thümliche, gabelige Fortsätze der Zellen bedingt, in welche die Nachbarzellen eingreifen; es bestehen deutliche Intercellularräume, eine Kittsubstanz fehlt. Die ganze Oberfläche der Zelle ist mit kleinen Zähnchen bedeckt; Verbindungsfäden zwischen zwei Zellen sind nicht mehr vorhanden. Die Abschilferung geschieht, durch Lockerung der Verkeilung, woran der Schweiss in hervorragender Weise betheiligt erscheint.

5. Alle Hornzellen zeigen vom Strat. gran. bis zur 0 berfläebe in Bezug a u $M$ embran, Faserwerk, Intercellularstruktur und Verhornungsgad den gleichen Bau. Umwandlungen betreffen nur das E le i d in, bz. das Pareleid in; dadurch wird wohl die verschiedene färberische Reaktion der einzelnen Lagen der Hornschicht bedingt.

6. Die Veränderung der beiden Körper wird auscheinend vor allem durch eine Imprägnation der Zellen mit dem $\mathrm{S} \mathrm{ch} \mathrm{w}$ e is s veranlasst.

7. Die Hornmembran entsteht durch Umwandlung des fibrillären Exoplasmas der Zellen des Strat. Malp. Das Fibrillennetz im Zellinnern wird durch die persistirenden Proto plasmafasern, die Fibrillarmasse, gebildet.

8. Das Eleidinentsteht durch Verflüsigung des Keratobyalins, der zerfallenen Interfibrillarsubstanz; Ursache dafur sind vielleicht in's Zellprotoplasma tretende, aufgelöste Produkte des Kernzerfalls.

9. Die 0 b e r fl ä c h e $\mathrm{n} z \ddot{a} \mathrm{~h} \mathrm{n}$ c h e $\mathrm{n}$ sind die veränderten Ranvier'schen Knötchen der Intercellularbrücken, die wahrscheinlich dabei einer Theilung in zwei Hälften unterliegen.

10. Von der in dieser Weise gehauten Hornschicht der Vola manus und Planta pedis unterscheidet sich diejenige der ubrigen Hautstellen. Deren Elemente sind kernlos, jedoch mit deutlichen Kernhöhlen versehen, völlig abgeplattet und zu Lamellen aneinandergeschlossen ohne Intercellularräume und Zähnchen. Die Verhornung beschränkt sich jedoch auch hier nur auf die Membran; ein Netzwerk im Innern fehlt; ebenso das Eleidin, das an einzelnen Stelleu jedoch sich in Spuren findet. 
11. Die Hornzelle entsteht anch hier durch Umwandlung aus den Zellen der tieferen Epidermislagen in derselben Weise wie an Vola manus und Planta pedis. Der Unterse hi ed i $\mathrm{m} \mathrm{Bau}$ is t kein principieller, sondern nur auf die Druck- und Z $7 \mathrm{~g}$ wirkung $\mathrm{zur}$ uck\%uführen, der die einzelnen Zellen wegen i hrer bedeutend geringeren Anzahl hier in stärkerem Masse unterliegen. 28. Januar 1900.

\section{Literatur - Verzeichniss.}

1. Aufhammer, Kritisirende Bemerkungen zul Schrön's Satz: Lo strato corneo trae la sua origine dalle ghiandole sudorifere. Verhandlungen der physik.-mediz. Gesellsch. zu Würzburg. 1869. I.

2. Behn, Studien über die Verhornung der menschlichen Oberhant. Arch. f. mikr. Anat. Bd. 39. 1892.

3. Beneke, Epithelfaserung der menschlichen Oberhaut. Verhandl. der Gesellsch. deutscher Naturf. und Aerzte zu Wien. 1894.

4. Biesiadecki, Hant, Haare und Nägel. Stricker's Handbuch der Lehre von den Geweben. 1871.

5. Bizzozero, Sulla struttura degli epiteli pavimentosi stratificati. Rendiconti del R. Istituto Lombardo. Vol. II. 1871. Ref. in Centralbl. f. med. Wissensch. 1871.

6. Böhm und Davidoff, Lehrbuch der Histologie des Menschen. 2. Aufl. 1898.

7. v. Brunn, Haut (Integumentum commune), Bardeleben's Handbuch der Anatomie des Menschen. 1897.

8. Buzzi, Keratohyalin und Eleidin. Monatshefte f. prakt. Dermat. 8. Bd. 1889.

9. Derselbe, Ueber Eleidin. Ebenda Bd. 23. 1896.

10. Dreysel und Oppler, Beitrïge zur Kenntniss des Eleidins in normaler und pathologisch veränderter Hant. Arch. f. Dermat. und Syphil. Bd. 30. 1895.

11. Eddowes, Ueber die Natur der Herxheimer'schen Spiralen der Oberhaut. Monatsschrift f. prakt. Dermat. Bd. 11. 1890.

12. Ehrmann, Ueber die Herxheimer'schen Fasern in der Epidermis. Arch. f. Dermat. und Syphil. Bd. 24. 1892.

13. Ernst, Ueber die Beziehung des Keratohyalins zum Hyalin. Virchow's Archiv Bd. 130. 1892.

14. Derselbe, Studien über normale Verhornung mit Hülfe der Gra m'schen Methode. Arch. f. mikr. Anat. Bd. 47. 1896.

15. Flemming, Neue Beiträge zur Kenntniss der Zelle. II. Theil. Arch. f. mikr. Anat. Bd. 37. 1891.

16. Derselbe, Morphologie der Zelle und ihre Theilungserscheinungen. Ergebnisse der Anat. und Entwicklungsgeseh. Bd. 3. 1893. Archiv f. mikrosk. Anat Bd. 56 
17. Derselbe, Ueher Intercellularlücken des Epithels und ihren Inhalt. Anat. Hefte Bd. 6. 1896.

18. Garten, Die Intercellularbrücken der Epithelien und ihra Function. Arch. f. Anat. und Physiol. Phys. Abtheil. 1895.

19. Gegenbaur, Lehrbuch d. Anatomie d. Menschen. 7. Aufl. 1899.

20. Grosse, Ueber Keratohyalin und Eleidin und ihre Beziehung zum Verhornungsprozesse. Inaug.-Diss. Königsberg 1892.

21. Her xheimer, Ueber eigenthümliche Fasern in der Epidermis und im Epithel gewisser Schleimhäute des Menschen. Archiv f. Dermat. und Syphil. Bd. 21. 1889.

22. Derselbe, Ueber die Structur des Protoplasmas der menschlichen Epiderminzelle. Arch. f. mikr. Anat. Bd. 53. 1899.

23. Derselbe, Nachtrag und Berichtigung zu meiner Arbeit: Ueber die Structur des Protoplasmas der menschlichen Epidermiszelle. Ebenda Bd. 54. 1899.

24. Her $x$ heimer und $M u ̈ l l e r$, Ueber die Deutung der sog. Epidermisspiralen. Arch. f. Dermat. nnd Syphil. Bd. 36. 1896.

25. Manille Ide, La membrane des cellules du corps muqueux de Malpighi. La Cellule. T. 4. 1888.

26. Ko elliker, Handbuch der Gewebelehre des Menschen. 6. Auf. 1889.

27. Kolossow, Eine Untersuchungsmethode des Epithelgewebes, bes. der Drüsenepithelien und die erhaltenen Resultate. Archiv f. mikr Anat. Bd. 52. 1898.

28. Kromayer, Ueber die Bedeutung der von Herxheimer im Epithel beschriebenen Fasern. Arch. f. Dermat. und Syphil. Bd.22. 1890.

29. Derselbe, Zur pathologischen Anatomie der Psoriasis nebst einigen Bemerkungen über den normalen Verhornungsprozess und die Structur der Stachelzelle. Ebenda.

30. Derselbe, Die Protoplasmafaserung der Epithelzelle. Arch. E. mikr. Anat. Bd. 39. 1892.

31. Derselbe, Zur Epithelfaserfrage. Monatshefte f. prakt. Dermat. Bd. 24. 1897.

32. Langerhans, Ueber Tastkörperchen und Rete Malpighi. Arch. f. mikr. Anat. Bd. 9. 1873.

33. Loeb, Ueber Regeneration des Epithels. Arch. f. Entwicklungsmechanik Bd. 6. 1898.

34. Loewy, Beiträge zur Anatomie und Physiologie der Oberhaut. Arch. f. mikr. Anat. Bd. 37. 1891.

35. Merk, Experimentelles zur Biologie der Haut. 1. Mittheil. Die Beziehungen der Hornschicht zum Gewebsafte. Sitzungsber. d. k. Akad. d. Wissensch. zu Wien. 1899.

36. Mertsching, Histologische Studien über Keratohyalin u. Pigment. Vii rehow's Archiv. Bd. 116. 1889.

37. Oehl, Indagini di anatomia microscopica per servire allo studio dell' epidermide e della cute palmare della mano. Annali universali di medicina. 1857. 
38. Philippson, Ueber Herstellung von Flichenbildern der Oberhaut und der Lederhaut. Monatsh. f. prakt. Dermat. Bd. 8. 1889.

39. Posner, Untersuchungen über Schleimhautverhornung (Pachydermia mucosae). Virch ow's Arch. Bd. 118. $18: 9$.

40. Rabl, Untersuchungen über die mensehliche Oberhaut und ihre Anhangsgebilde mit bes. Rücksicht auf die Verhornung. Arch. $f$. mikr. Anat. Bd. 48. 1897.

41. Derselbe, Bleiben die Protoplasmafasern in der Körnerschicht der Oberhaut erhalten? Arch. f. Dermat. u. Syphil: Bd. 41. 1897.

42. Derselbe, Haut. Ergebnisse der Anat. und Entwicklung'sgesch. Bd. 7. 1897.

43. Ramon y Cajal, Contribution à l'étude des ce!lules anastomosées des épithéliums pavimenteux stratifiés. Internat. Monatschr. für Anat. und Histol. Bd. 3. 1886.

44. Ranvier, Sur une substance nouvelle de l'épidërme et sur le processus de kẻratisation du revêtement épidermique. Comptes rendus de l'Academ. des sciences. T. 88, 1879.

45. Derselbe, Nouvelles recherches sur le mode d'union des cellules du corps umqueux de Malpighi. Ebenda T. 89. 1879.

46. Derselbe, Sur la structure des cellules des corps muqueux de Malpighi. Ebenda. T. 95. 1882.

47. Derselbe, Histologie de la peau. Arch. d'anatomie microscopique. T. 3. 1899.

48. Rauber, Lehrbuch der Anatomie des Menschen. 5. Aufl. 1898.

49. Rausch, Tinctorielle Verschiedenheit und Relief der Hornzellen. Monatsh. f. prakt. Dermat. Bd. 24. 1897.

50. Reinke, Zellstudien. Arch. f. mikr. Anat. Bd. 43. 1894.

51. Renaut, Sur les fibres unitives des cellules du corps muqueux de Malpighi. Associat. franç. pour l'avancement des sciences. 14 e Session. 1885.

52. Retzius und Key, Zur Kenntniss der Saftbahnen in der Haut des Menschen. Biologische Untersuchungen. 1881.

53. Rosenstadt, Ueber das Epitrichium des Hühnchens. Archiv f. mikr. Anat. Bd. 49.1897.

54. Schütz, Ueber den Nachweis des Zusammenhangs der Epithelien mit dem darunter liegenden Bindegewebe in der Haut des Menschen. Arch. f. Dermat. und Syphil. Bd. 36. 1896.

55. Selhorst, Ueber das Keratohyalin und den Fettgehalt der Haut. Inaug.-Dissert. Berlin 1890.

56. Stöhr, Lehrbuch der Histologie. 8. Aufl. 1898.

57. Studnička, Ueber die intercellularen Verbindungen, den sog. Kuticularsaum und den Flimmerbesatz der Zellen. Sitzungsber: d. böhm. Gesellsch. d. Wissensch. 1898.

58: Tettenhammer, Ueber die Entstehung der acidophilen Leukocytengranula ans degenerirender Kernsubstanz. Anat. Anzeiger Bd. 8. 1893. 
59. Unna, Entwicklung'sgeschichte und Anat. der Haut. Ziemssen's Handbuch der Hautkrankheiten. 1882.

60. Derselbe, Die Färbung der Epithelfasern. Mouatsh. für prakt. Dermat. Bd. 19. 1894.

61. Derselbe, Ueber Protoplasmafärbung nebst Bemerkungen über die Bindegewebszelle der Kutis. Ebenda.

62. Derselbe, Die spezifische Färbung d. Epithelprotoplasmas. Ebenda.

63. Derselbe, Ueber das Wesen der normalen und pathologischen Verhornuing. Ebenda Bd. 24.1897.

64. d'Urso, Giorn. nat. Nap. I. 1 u. 2 (citirt nach Ernst 13).

65. Waldeyer, Untersuchungen über dic Histogenese der Horngebilde, im bes. der Haare u. Federn. Beitrige zur Anat. u. Embryologie. Henle'sche Festgabe 1882.

66. Zander, Untersuchungen über den Verhornungsprozess. II. Mitthlg. Der Bau der menschlichen Epidermis. Arch. f. Anat. und Physiol. Anatom. Abtheilg. 1888.

\section{Erklärung der Abbildungen anf Tafel VII a. VIII.}

(Wo nicht anders bemerkt, entstammen die Prïparate der Vola manus des erwachsenen Menschen.)

Fig. 1. Basaltheil des Strat. Malp. mit angrenzender Kutis. Alkoholfixation. Färbung mit Eisenhämatoxylin nach Heidenhain. Nachfürbung mit Rubin S. Zeiss. Ap. 2 mm, Oc. 6.

Fig. 2. Zelle des Strat. Malp. Härtung und Färbung wie Fig. 1. Zeiss. Ap. $2 \mathrm{~mm}$, Oc. 12.

Fig. 3. Parthie aus dem Strat. Malp, Alkoholfixation. Fürbung nach Kromayer. Zeiss. Ap. $2 \mathrm{~mm}$, Oc. 6.

Fig. 4. Parthie aus dem Strat. Malp. Formolfixation. Färbung mit Eisenhämatoxylin. Nachfärbung mit Rubin S. Z e is s. Ap. $2 \mathrm{~mm}$, Oc. 8 .

Fig. 5. Zellen des Strat. Malp. von der Plantarhaut der Katzenpfote. Fixation in Zenker'scher Flüssigkeit. Färbung wie Fig. 4. Zeiss. Ap. $2 \mathrm{~mm}$, Oc. 6.

Fig. 6. Zellen aus dem basalsten Theil des Strat. granulos. Fixirung und Färbung wie Fig. 4. Vorfärbung mit Bordeaux. Zeiss. Ap. $2 \mathrm{~mm}$, Oc. 6 .

Fig. 7. Parthie aus dem Strat. gran, der Plantarhaut der Katzenpfote (aus demselben Schnitt wie Fig. 5). Fixation wie Fig. 5, Färbung wie Fig 4. Zeiss. Ap. $2 \mathrm{~mm}$, Oc. 6.

Fig. 8. Zellen aus dem Strat. gran. Fixation in Zenker'scher Flüssigkeit. Färbung nach Kromayer. Zeiss. Ap. 2 mm, Oc. 4.

Fig. 9. Zellen aus dem Strat. gran. Fixirung und Färbung wie Fig. 1. Zeiss. Ap. $2 \mathrm{~mm}$, Oc. 12.

Fig. 10. Durch Maceration isolirte Zellen der Sohlenhaut. Färbung mit Methylviolett. Zeiss, Ap. $2 \mathrm{~mm}$, Oc. 4. 
Fig. 11. Durch Verdauungsflüssigkeit isolirte Zellen der Sohlenhaut. Ungefärbt. Leitz. Obj. 5, Oc. 4.

Fig. 12. Durch Verdauungsflïssigkeit isolirte Zellen der Hüftenhaut. Ungefärbt. Leitz. Obj. 5. Oc. 4.

Fig. 13. Durch Verdauungsflüssigkeit isolirte Zellen aus der Hüftenhaut. Färbung mit Methylviolett. Leitz. Obj. 5, Oc. 4.

Fig. 14. Durch Maceration isolirte Zellen der Sohlenhaut. Färbung. mit polychroms. Methylenblau nach Rausch. Zeiss. Ap. $2 \mathrm{~mm}$, Oc. 4.

Fig. 15. Schnitt durch das Strat. corneum. Alkoholfixation. Eisenhämatoxylinfärbung. Z eiss. Ap. $2 \mathrm{~mm}$, Oc. 8.

Fig. 16. Hornzelle des Strat. disjunctum. Aus demselben Schnitt wie Fig. 15. Z e iss. Ap. $2 \mathrm{~mm}$, Oc. 12 .

Fig. 17. Intercellularstructur der Hornzellen. Aus demselben Schnitt wie Fig. 15. Zeiss. Ap. $2 \mathrm{~mm}$, Oc. 12.

Fig. 18. Schnitt durch in toto verdaute Epidermis von der Hüfte. Alkoholfixation. Hämalaunfärbung. Ze iss. Ap. 2 mm, Oc. 2.

Fig. 19. Aneinanderstossende Hornzellen einer seitlich umgeklappten Lamelle der vorhergehenden Figur. Zeiss. Ap. 2 mm, Oc. 4.

Fig. 20. Zelle aus dem Strat. corneum. Alkoholfixation. Eisenhämatoxylinfärbung. Zei ss. Ap. 2 mm, Oc. 6 .

Fig. 21. Zellen aus einem Schnitt durch das Strat. corn. Fixation in Zenker'scher Flüssigkeit. Färbung nach Kromayer. Zeiss. Ap. $2 \mathrm{~mm}$, Oc. 4.

Fig. 22. Zellen aus dem mittl. Theil der Hornschicht eines in toto verdauten Stückes Sohlenhaut. Fixation und Färbung wie Fig. 20. Leitz. Obj. 7, Oc. 4.

Fig. 23. Zellen von der iussersten Peripherie eines in toto verdauten Stückes Sohlenhaut. Fixation, Färbung, Vergrösserung wie Fig. 22.

Fig. 24. Hornschicht der Sohlenhaut nach Schnittverdauung. Hämalaunfärbung. Leitz. Obj. 7, Oc. 4.

Fig. 25. Hornschicht der Hüftenhaut nach Schnittverdauung. Hämalaunfärbung. $Z$ e iss. Ap. $2 \mathrm{~mm}$, Oc. 4.

Fig. 26. Parthie aus der Grenzschicht $z w$. Strat. gran. und lucid. (Strat. intermed. Ranvier's). Aus demselben Schnitt wie Fig. 15. Eisenhämatoxylinfärbung. Z e iss. Ap. $2 \mathrm{~mm}$, Oc. 6.

Fig. 27. Zelle aus derselben Zone. Alkoholfixation. Färbung nach Kromayer. Zeiss. Ap. 2 mm, Oc. 8.

Fig. 28. Parthie aus derselben Zone. Formolfixation. Färbung mit Hämalaun und Pikrinsäure-Fuchsin nach van Gieson. Zeiss. Ap. $2 \mathrm{~mm}$, Oc. 6.

Anmerk. Die Fig. 4, 10 und 13 entsprechen im Farbenton nicht genau den Präparaten; auch ist in Fig. 13 die Oberflächengranulirung zu stark ausgeprägt wiedergegeben. 